\title{
The Interplay Between Peroxiredoxin-2 and Nuclear Factor-Erythroid 2 Is Important in Limiting Oxidative Mediated Dysfunction in $\beta$-Thalassemic Erythropoiesis
}

\author{
Alessandro Matte, Luigia De Falco, ${ }^{2}$ Achille Iolascon, ${ }^{2}$ Narla Mohandas, ${ }^{3}$ Xiuli An, ${ }^{3}$ \\ Angela Siciliano, Christophe Leboeuf, ${ }^{4}$ Anne Janin, ${ }^{4-6}$ Mariasole Bruno, ${ }^{1,2}$ Soo Young Choi, \\ Dae Won Kim, ${ }^{7}$ and Lucia De Franceschi ${ }^{1}$
}

\begin{abstract}
Aims: $\beta$-Thalassemia is a common inherited red cell disorder characterized by ineffective erythropoiesis and severe oxidative stress. Peroxiredoxin-2 (Prx2), a typical 2-cysteine peroxiredoxin, is upregulated during $\beta$ thalassemic erythropoiesis, but its contribution to stress erythropoiesis, a common feature of thalassemia, is yet to be fully defined. Results: Here, we showed that $\operatorname{Pr} 2^{-/-}$mice displayed reactive oxygen species related abnormalities in erythropoiesis similar to that of $\mathrm{Hbb}^{\text {th } 3 /+}$ mice associated with activation of redox response transcriptional factor nuclear factor-erythroid 2 (Nrf2). We generated $\beta$-thalassemic mice genetically lacking $\operatorname{Prx} 2\left(\operatorname{Prx} 2^{-/-} \mathrm{Hbb}^{\text {th } 3 /+}\right)$ and documented a worsened $\beta$-thalassemic hematological phenotype with severe ineffective erythropoiesis. To further validate a key role of Prx2 in stress erythropoiesis, we administrated fused recombinant PEP1Prx2 to $\mathrm{Hbb}^{\text {th } 3 /+}$ mice and documented a decrease in ineffective erythropoiesis. We further show that Prx2 effects are mediated by activation of Nrf2 and upregulation of genes that protect against oxidative damage such as gluthatione S-transferase, heme-oxygenase-1, and NADPH dehydrogenase quinone- 1 . Innovation: We propose Prx 2 as a key antioxidant system and Nrf2 activation is a cellular adaptive process in response to oxidative stress, resulting in upregulation of antioxidant (antioxidant responsive element) genes required to ensure cell survival. Conclusion: Our data shed new light on adaptive mechanisms against oxidative damage through the interplay of Prx 2 and Nrf2 during stress erythropoiesis and suggest new therapeutic options to decrease ineffective erythropoiesis by modulation of endogenous antioxidant systems. Antioxid. Redox Signal. 23, 1284-1297.
\end{abstract}

\section{Introduction}

$\mathbf{E}$ RYTHROPOIESIS IS a complex multistep process in which erythroid progenitors undergo terminal erythroid differentiation to generate erythroblasts and reticulocytes. In spite of the progresses made in molecular characterization of normal erythropoiesis, much still remains to be investigated about the mechanisms involved in disordered erythropoiesis $(2,13,28)$. Erythroid differentiation is characterized by the production of reactive oxygen species (ROS) both in re- sponse to erythropoietin and as a consequence of the large amount of iron imported into the cells for heme biosynthesis. Thus, in erythropoiesis, efficient cytoprotective systems are required to limit possible ROS related toxic effects as evidenced by the severe hematological phenotype of superoxide dismutase 2 null embryos and perturbation of erythropoiesis in juvenile $\operatorname{Prx} 2^{-/-}$mice $(14,27,32)$.

Peroxiredoxin-2 (Prx2) is a typical 2-cysteine peroxiredoxin that is able to efficiently scavenge a low concentration of $\mathrm{H}_{2} \mathrm{O}_{2}$ without inactivation due to over-oxidation $(9 \mathrm{a}, 21$,

${ }^{1}$ Department of Medicine, University of Verona-AOUI Verona, Verona, Italy.

${ }^{2}$ CEINGE and Department of Biochemistry, University of Naples, Naples, Italy.

${ }^{3}$ New York Blood Center, New York, New York.

${ }^{4}$ Inserm, U1165, Paris, France.

${ }^{5}$ Université Paris 7, Denis Diderot, Paris, France.

${ }^{6}$ AP-HP, Hôpital Saint-Louis, Paris, France.

${ }^{7}$ Institute of Bioscience and Biotechnology, Hallym University, Chuncheon, Korea. 


\begin{abstract}
Innovation
$\operatorname{Prx} 2^{-1-}$ mice show abnormal erythropoiesis similar to that seen in $\beta$-thalassemia, and the absence of peroxiredoxin-2 (Prx2) worsens ineffective erythropoiesis of $\beta$ thalassemia. Prx $2^{-1-}$ and $\mathrm{Hbb}^{3 \mathrm{th} /+}$ mice show activated nuclear factor-erythroid 2 and upregulation of antioxidant responsive element-containing genes of antioxidant systems to reduce oxidant damage. Fused recombinant Prx2 fused to cell-penetrating carrier cell-penetrating peptides (PEP1) peptide ameliorates $\mathrm{Hbb}^{3 \mathrm{th} /+}$ hematological phenotype and erythropoiesis.
\end{abstract}

29, 33). Although progress has been made in functional characterization of $\operatorname{Prx} 2$ as an antioxidant system in erythrocytes and in various cell models $(29,50)$, much still remains to be investigated on the role of Prx 2 during erythropoiesis. Recently, we reported that Prx 2 expression is upregulated during both murine and human $\beta$-thalassemic erythropoiesis, suggesting a potential functional role for Prx 2 to serve as the stress-response cytoprotective system in pathological erythropoiesis $(7,9 \mathrm{a}, 13,21,33)$. In other cell models, Prx 2 expression has been reported to be under the control of different transcriptional factors such as nuclear factor-erythroid 2 (Nrf2) (45), Foxo3a (37), STAT3 (47), and NF-kB (49).

$\beta$-Thalassemias are common inherited red cell disorders characterized by absent or reduced synthesis of $\beta$ globin chains. Despite extensive knowledge of the molecular defects causing thalassemia(s), less is known about the mechanisms responsible for the associated ineffective erythropoiesis (44). Increased levels of ROS have been reported to contribute to the anemia of $\beta$ thalassemia; however, the protective mechanisms against oxidative stress in $\beta$ thalassemia have not been comprehensively addressed $(1,17)$.

Activation of redox-sensitive transcriptional factors such as Nrf2, which induces transcription of antioxidant genes (18), has been implicated as the physiological cellular response to acute and/or chronic oxidative stress in different cell types. Nrf2 is ubiquitously expressed and binds to the antioxidant responsive element (ARE), sustaining the induction of cytoprotective genes such as heme-oxygenase-1 (HO-1) or NAD(P)H dehydrogenase quinone 1 (nqo1), Prx1, and Prx6 $(30,46)$. The upregulation of these systems limits the ROS generation, thereby contributing to cellular resistance and survival against cytotoxic events such as oxidative stress-mediated cytotoxic events. It is of interest to note that $N r f 2$ is also involved in the expression of sulfiredoxin (Srxn), thioredoxin reductase (Txnrd), and sestrin2 (Sesn2), which are systems involved in reversing Prx2 over-oxidation $(22,30,41,48)$. Mice genetically lacking Nrf2 develop an immune-mediated anemia with the age and show reduction in the expression of ARE-genes in the spleen (26).

In this study, we sought to determine the role of Prx 2 as a redox-switch protein during erythroid maturation by focusing on stress erythropoiesis. Our goal was to examine whether the absence of Prx 2 in the context of thalassemic background ( $\operatorname{Prx} 2^{-/-} \mathrm{Hbb}^{\text {th3/+ }}$ ) will impact pathological erythropoiesis, a physiologically relevant model of stress erythropoiesis. We report that the absence of $\operatorname{Prx} 2$ is as- sociated with (i) ineffective erythropoiesis; (ii) increased ROS levels in erythroid precursors; and (iii) activation of Nrf2 with upregulation of Nrf2-activated antioxidant genes such as HO-1. We propose that Prx2 co-operates with Nrf2 and acts as an adaptive mechanism to protect against severe oxidative stress. In fact, the extent of Nrf2 activation was higher in Prx $2^{-1-} \mathrm{Hbb}^{\text {th } 3 /+}$ erythroid precursors compared with either normal or $\mathrm{Hbb}^{\text {th } 3 /+}$ erythroid precursors. The administration of the recombinant protein PEP1Prx2, in which Prx2 is fused to cell-penetrating carrier cell-penetrating peptides (PEP1) peptide $(5,20)$, to $\mathrm{Hbb}^{\text {th } 3 /+}$ mice decreased the extent of ineffective erythropoiesis with a significant reduction in ROS levels and apoptosis. Our data suggest that Prx2 is a key cytoprotective system in stress erythropoiesis and in conjunction with Nrf2 to limit amplification of oxidative damage in $\beta$-thalassemia. These findings suggest potential novel therapeutic options for treatment of $\beta$-thalassemia through the modulation of endogenous antioxidant systems to overcome the imbalance between oxidative stress and cytoprotective mechanisms.

\section{Results}

\section{Prx2 $^{--}$mice show ineffective erythropoiesis}

Previous studies have shown that the absence of $\operatorname{Prx} 2$ results in chronic hemolytic anemia with splenomegaly and increased basophilic erythroblasts in $\operatorname{Prx} 2^{-/-}$juvenile mice (25). In this study, we used the recently developed flow cytometry strategy that combines CD44, TER119, and cell size as markers to quantitate terminal erythroid differentiation. We used the same strategy to sort erythroid precursors at each distinct developmental stage (Population I: pro-erythroblasts; population II: basophilic erytroblasts; population III: polychromatic erythroblasts; population IV: orthochromatic erythroblasts) $(13,28)$. As shown in Figure 1A, Prx $2^{-/-}$erythroid cells showed an irregular nuclear shape and decreased nuclear condensation, nuclear fragmentation, and multinuclear erythroblasts, cellular features characteristic of dyserythropoiesis. This was associated with extramedullary erythropoiesis as evidenced by increased erythropoietic activity in Prx $2^{-l-}$ spleen (Supplementary Fig. S1A; Supplementary Data are available online at www.liebertpub.com/ars). In fact, mouse spleen is a key site for extramedullary erythropoiesis in response to either stress erythropoiesis $(3,42)$. No significant differences in the process of terminal erythroid differentiation between control and Prx $2^{-/-}$bone marrow were evident (Fig. 1B).

$\beta$-Thalassemia is a paradigmatic model of ineffective erythropoiesis with dyserythropoiesis mainly related to oxidative stress $(7,43) . \mathrm{Hb}^{\text {th } 3 /+}$ mice showed dyserythropoiesis and ineffective erythropoiesis with expansion of erythroid precursors with extramedullary erythropoiesis (Fig. 1A, B). In bone marrow of $\mathrm{Hbb}^{\text {th } 3 /+}$ mice, we found a significant reduction in basophilic erythroblasts (pop II) and polychromatic erythroblasts (pop III) and increased orthochromatic erythroblasts compared with wild-type (WT) mice (Fig. 1B). The maturation profile of erythroid populations from the spleen of Prx $2^{-l-}$ and $\mathrm{Hbb}^{\mathrm{th} 3 /+}$ mice was similar (Fig. 1B). These data suggest that the absence of Prx 2 promotes ineffective erythropoiesis with expansion of erythroid precursors similar to $\beta$-thalassemia. To test this hypothesis, we evaluated ROS levels during erythropoiesis in $\operatorname{Prx} 2^{-1-}$ and $\mathrm{Hbb}^{\text {th } 3 /+}$ mice compared with WT. 
A

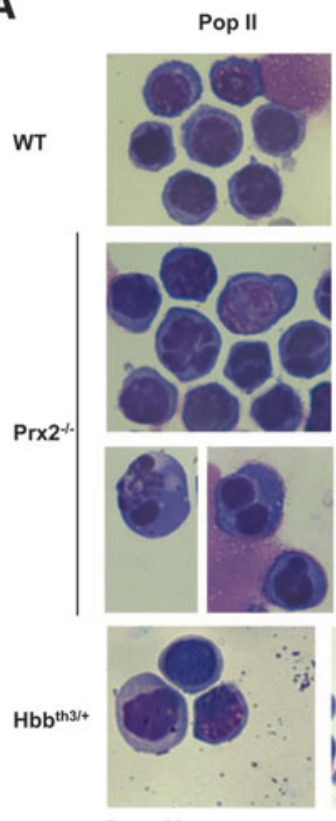

Bone Marrow

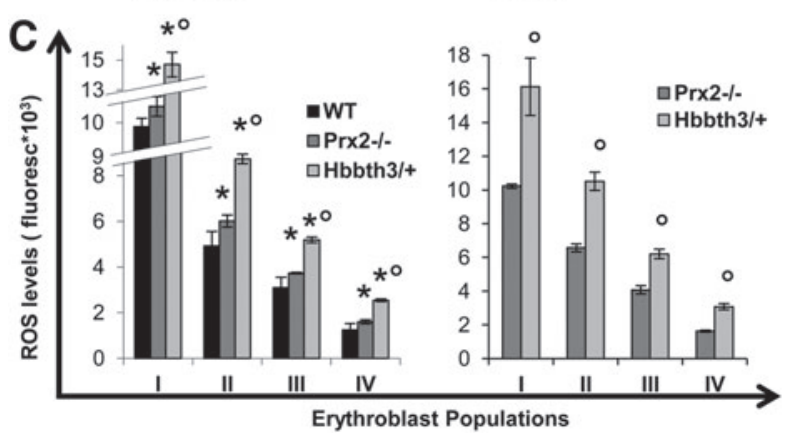

Pop IV
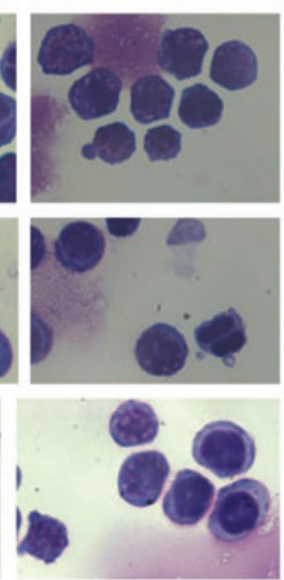

Spleen
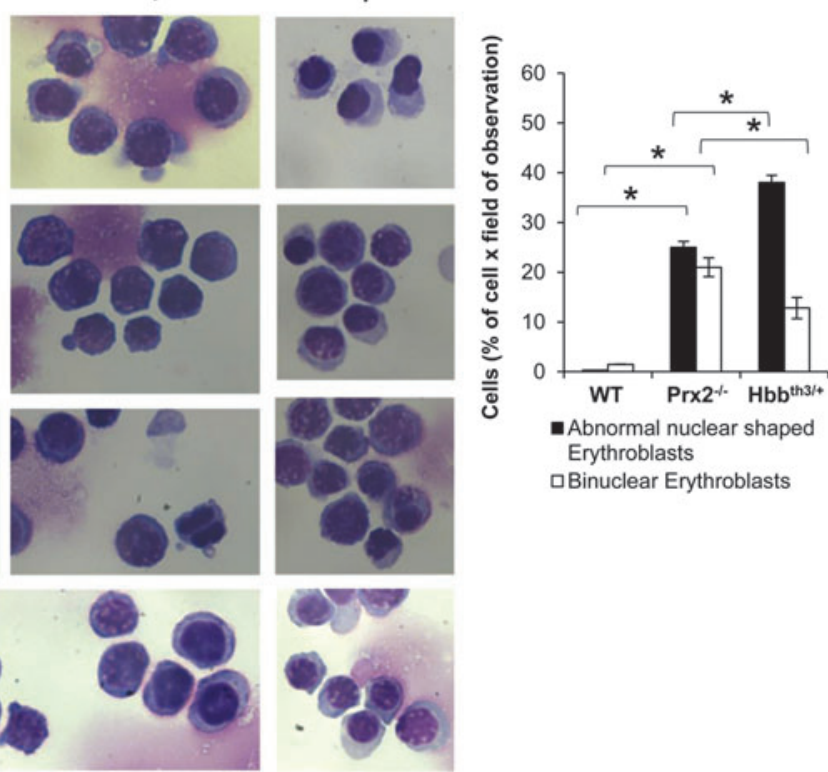

B

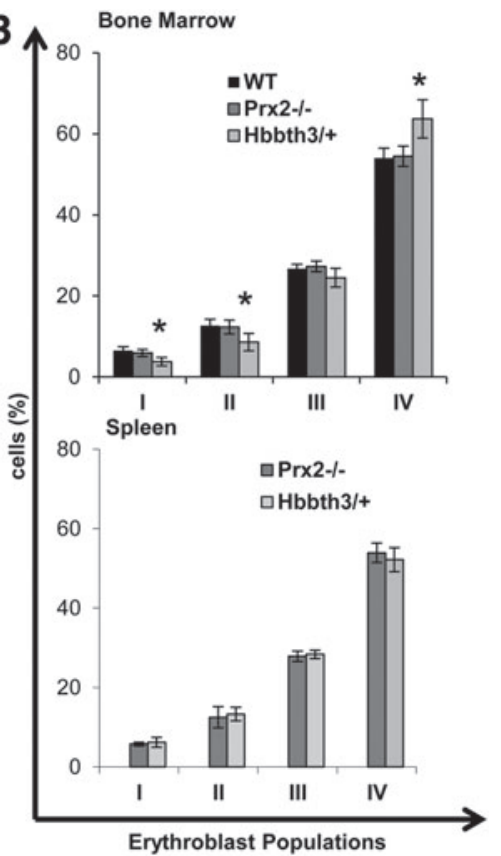

D

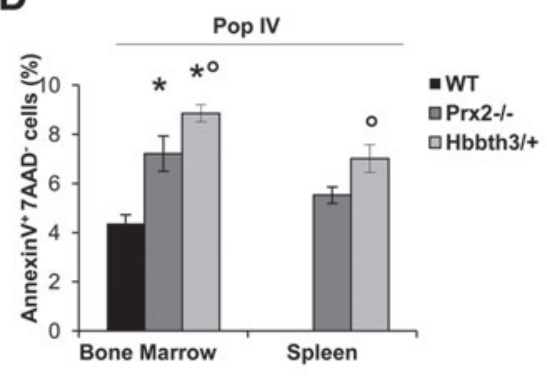

FIG. 1. Prx $2^{-/-}$mice show ineffective erythropoiesis similar to $\beta$-thalassemia $\left(\mathbf{H b b}^{\text {th } 3 /+}\right.$ mice). (A) Left panel. Morphology of sorted erythroid from WT, Prx $2^{-/-}$and $\mathrm{Hbb}^{\text {th } 3 /+}$ mice. Cytospins were stained with May-GrunwaldGiemsa. Cells were imaged under oil at $100 \times$ magnification using a Panfluor objective with 1.30 numeric aperture on a Nikon Eclipse DS-5M camera and processed with Digital Slide (DS-L1) Nikon. One representative image from a total of 10 for each mouse strains. Right panel. Abnormal nuclear-shaped erythroblasts and binuclear erythroblasts from WT, Prx $2^{-1-}$, and $\mathrm{Hbb}^{\text {th } 3 /+}$ mice evaluated on cytospin stained with May-Grunwald-Giemsa. Data are presented as means \pm SD $(n=10$ from each strain); * $p<0.05$ compared with WT. (B) Cyto-fluorimetric analysis of maturation pattern of erythroid precursors from the bone marrow (upper panel) and spleen (lower panel) of WT Prx $2^{-/-}$and $\mathrm{Hbb}^{\text {th } 3 /+}$ mice using the following surface markers: CD44 and TER119 (see Supplementary Materials and Methods and Supplementary Fig. S1A). This cyto-fluorimetric strategy allows the identification of the following homogenous cell populations: population I corresponding to pro-erythroblasts; population II corresponding to basophilic erythroblasts; population III corresponding to polychromatic erythroblasts; and population IV corresponding to orthochromatic erythroblasts. Data are presented as means \pm SD $(n=12) ; * p<0.05$ compared with WT. (C) ROS levels in erythroid precursors from bone marrow (left panel) and spleen (right panel) of WT, Prx $2^{-1-}$, and $\mathrm{Hbb}^{\text {th } 3 /+}$ mice. Data are presented as means $\pm \mathrm{SD}\left(n=12\right.$ from each strain); ${ }^{*} p<0.05$ compared with WT; ${ }^{\circ} p<0.05$ compared with Prx $2^{-l-}$. (D) Amount of Annexin $\mathrm{V}^{+}-7-\mathrm{AAD}^{-}$cells (early apoptosis) on sorted orthochromatic erythroblasts (population IV) from either bone marrow of WT, Prx $2^{-/-}$, and $\mathrm{Hbb}^{\text {th } 3 /+}$ mice or spleen of Prx $2^{-/-}$and $\mathrm{Hbb}^{\text {th } 3 /+}$ mice. Data are presented as means $\pm \mathrm{SD}$ ( $n=8$ from each strain); ${ }^{*} p<0.05$ compared with $\mathrm{WT}$; ${ }^{\circ} p<0.05$ compared with Prx $2^{-l-}$ mice. 7-AAD, 7aminoactinomycin D; Prx2, peroxiredoxin-2; ROS, reactive oxygen species; SD, standard deviation; WT, wild type. To see this illustration in color, the reader is referred to the web version of this article at www.liebertpub.com/ars

ROS levels and apoptotic cells are increased in erythroid precursors from Prx2 ${ }^{-/-}$mice

As shown in Figure 1C, ROS levels were significantly increased in bone marrow basophilc and polychromatic erythroblasts from Prx $2^{-l-}$ compared with WT mice. Such an increase in ROS levels was a feature of erythroid populations at all different stages of terminal erythroid differentiation from Prx $2^{-l-}$ mouse spleens (Fig. 1C). The finding of increased ROS levels only in basophilic and polychromatic erythroblasts from bone marrow of $\operatorname{Pr} \times 2^{-1-}$ mice may be related to different mechanisms involved in heme biosynthesis in the bone marrow and spleen involving macrophages. This is in agreement with our recent observation that Prx2 binds heme in erythroid precursors (6). In $\mathrm{Hbb}^{\text {th } 3 /+}$ mice, we found significant increased ROS levels in all erythroid 
populations from bone marrow and spleen compared with either WT or Prx $2^{-1-}$ mice (Fig. 1C). This might be related to the combination of different factors contributing to ROS accumulation in $\mathrm{Hbb}^{\text {th } 3 /+}$ erythroblasts such as iron import, heme biosynthesis, and the imbalance in globin-chain synthesis. To evaluate whether apoptosis might contribute to ineffective erythropoiesis in $\operatorname{Prx} 2^{-/-}$similar to that observed in $\mathrm{Hbb}^{\text {th } 3 /+}$ mice, we evaluated the amount of Annexin- $\mathrm{V}^{+} 7-$ aminoactinomycin D (7-AAD)-negative cells used to define early apoptotic cells. As shown in Figure 1D, we found a significant increase in apoptotic orthochromatic erythroblasts in both Prx $2^{-/-}$and $\mathrm{Hbb}^{\text {th } 3 /+}$ mice compared with WT. Similar changes were also noted in the orthochromatic erythroblasts from $\mathrm{Prx}^{-1-}$ and $\mathrm{Hbb}^{\text {th } 3 /+}$ mouse spleens. The amount of apoptotic orthochromatic erythroblasts was higher in $\mathrm{Hbb}^{\mathrm{th} 3 /+}$ than in Prx $2^{-/-}$mice (Fig. 1D).

These data suggest that the absence of Prx2 sustains ineffective erythropoiesis with increased ROS production and apoptosis compared with WT mice and partially mimicking $\mathrm{Hbb}^{\text {th } 3 /+}$ mice.

In order to test the link between the ineffective erythropoiesis of $\operatorname{Prx} 2^{-/-}$mice and increased oxidative stress, $\operatorname{Prx} 2^{-/-}$mice were treated with $N$-acetyl-cysteine (NAC) as an exogenous antioxidant, which has been previously shown to ameliorate $\mathrm{Hbb}^{\text {th } 3 /+}$ erythropoiesis (31). In $\operatorname{Prx} 2^{-/-}$mice, NAC significantly increased hematocrit (Hct) and hemoglobin $(\mathrm{Hb})$ levels and reduced splenic erythropoiesis (Supplementary Fig. S1B, C).

These data indicate that the ineffective erythropoiesis of $\operatorname{Prx} 2^{-1-}$ mice is related to increased ROS production similar to that observed in $\mathrm{Hbb}^{\text {th } 3 /+}$ mice. However, the preservation of erythropoietic activity of $\operatorname{Pr} \times 2^{-/-}$mice in the absence of Prx 2 suggests that the activation of additional adaptive mechanism(s) against the chronic oxidative stress is likely to ensure erythroblast survival and maturation.

\section{Prx2 $^{-1-}$ mouse erythroid precursors show activation of Nrf2 and upregulation of cytoprotective genes in response to oxidative stress}

Recent studies using other cellular models have pointed out a critical role of $\mathrm{Nrf} 2$, a redox-related transcriptional factor that induces the upregulation of antioxidant genes in response to oxidative stresses $(18,36)$. In this context, we found increased nuclear localization of Nrf2 in polychromatic and orthochromatic $\operatorname{Prx} 2^{-/-}$and $\mathrm{Hbb}^{\text {th } 3 /+}$ erythroblasts compared with WT (Fig. 2A). This was confirmed by immunoblot analysis with specific antibodies, showing increased active Nrf2 (phosphor-Nrf2-S40; P-Nrf2) (39) and total Nrf2 in Prx $2^{-/-}$compared with WT (Fig. 2B). To validate both the immunostaining and immunoblot data on Nrf2 activation and nuclear localization, we analyzed Nrf2 in cytosolic and nuclear fractions from flow sorted erythroid precursors. As shown in Supplementary Figure S1D, Nrf2 nuclear localization was increased in $\operatorname{Prx} 2^{-/-}$compared with WT mice, further validating Nrf2 activation in $\operatorname{Prx} 2^{-/-}$mice. As it has been previously reported that Nrf2 is activated only in response to oxidative stress $(18,19)$, it is not surprising that WT erythoblasts express low levels of active Nrf2 (Fig. 2B). In order to test the inducability of Nrf2 in WT mice in response to oxidation, we treated WT mice with phenylhydrazine (PHZ) to induce a severe oxidation damage, mimicking the $\beta$-thalassemic hematological phenotype (31). As shown in Supplementary Figure S1C, PHZ (40 mg/kg ip) induced a dramatic drop in Hct levels at day 2 after PHZ injection followed by the gradual recovery, reaching baseline values 13 days after PHZ treatment. At day 2 after PHZ injection, we found increased nuclear localization of Nrf2 in both polychromatic and orthochromatic erythroblasts from PHZ-treated WT compared with vehicle-treated WT mice (Supplementary Fig. S2B), supporting the transient activation of $\mathrm{Nrf} 2$ in response to oxidative stress.

The increased activation of Nrf2 in Prx $2^{-/-}$and $\mathrm{Hbb}^{\mathrm{th} 3 /+}$ erythroid precursors was associated with upregulation of $\mathrm{HO}$ 1 gene expression, an ARE-redox-sensitive gene (Fig. 2C). Prx $2^{-/-}$mice showed increased expression of HO- 1 in both polychromatic and orthochromatic erythroblasts compared with WT (Fig. 2C), whereas $\mathrm{Hbb}^{\text {th } 3 /+}$ mice showed increased Hmox-1 mRNA levels only in polychromatic erythroblasts (Fig. 2C). These data indicate that Prx $2^{-/-}$and $\mathrm{Hbb}^{\text {th } 3 /+}$ mice are characterized by increased oxidative stress and constitutive activation of Nrf2 during erythropoiesis. In contrast, in WT erythroid precursors Nrf2 is only transiently activated in response to exogenous oxidative damage.

We finally evaluated the expression of Srxn, Txnrd, and Sesn2, which are important systems in preventing Prx2overoxidation $(22,30,41,48)$. In $\mathrm{Hbb}^{\text {th } 3 /+}$ mouse polychromatic erythroblasts, Txnrd and Sesn 2 expression was similar to WT mice and upregulated compared with $\operatorname{Pr} \times 2^{-1-}$ mice, whereas Srxn expression was downregulated compared with WT. In $\mathrm{Hbb}^{\text {th } 3 /+}$ mouse orthochromatic erythroblasts, Srxn, Txnrd and Sesn2 were markedly upregulated compared with either WT or Prx $2^{-/-}$mice (Supplementary Fig. S3), indicating Sesn2 and Txnrd as main Prx2 repairing systems in polychromatic $\mathrm{Hbb}^{\text {th } 3 /+}$ mouse erythroblasts and all three, Srxn, Txnrd, and Sesn2, in $\mathrm{Hbb}^{\text {th } 3 /+}$ mouse orthochromatic erythroblasts.

Our data suggest that the activation of Nrf2 may act as a back-up mechanism providing an interface between oxidative stress and erythropoiesis but in the absence of Prx 2 such as in $\operatorname{Prx} 2^{-1-}$ or when upregulation of Prx 2 expression is insufficient to face oxidative stress such as in $\mathrm{Hbb}^{\text {th } 3 /+}$ mice it makes a contribution to limit damage. To explore whether the absence of Prx 2 might worsen in vivo $\mathrm{Hbb}^{\text {th } 3 /+}$ erythroid phenotype resulting in further activation of $\mathrm{Nrf} 2$, we generated a $\beta$ thalassemic mice knockout for Prx2 (Prx $2^{-/-} \mathrm{Hbb}^{\text {th } 3 /+}$ ).

\section{The absence of Prx2 worsens $\beta$-thalassemic hematologic phenotype, ineffective erythropoiesis, increased ROS levels, and apoptosis}

In Prx $2^{-1-} \mathrm{Hbb}^{\text {th } 3 /+}$ mice, the absence of Prx 2 worsened the hematological phenotype of $\beta$-thalassemic mice (Table 1; Figs. 3 and 4; and Supplementary Table S2). This is reflected by (i) the increased splenomegaly (Fig. 3A); (ii) increased amount of Fsc ${ }^{\text {high }} \mathrm{CD} 44^{+}$Ter1 $19^{+}$cells (Fig. 3B); and (iii) increased iron staining in the spleen of Prx $2^{-1-} \mathrm{Hbb}^{\text {th } 3 /+}$ compared with either Prx $2^{-/-}$or $\mathrm{Hbb}^{\text {th } 3 /+}$ mice (Fig. 3C). Prx $2^{-1-} \mathrm{Hbb}^{\text {th } 3 /+}$ also showed increased iron levels in the liver, which was mainly sequestered in Kupffer cells without signs of liver fibrosis (Fig. 3C). This was also associated with more severe signs of dyserythropiesis in Prx $2^{-1-} \mathrm{Hbb}^{\text {th } 3 /+}$ compared with $\mathrm{Hbb}^{\text {th } 3 /+}$ mice (Fig. 4A). Although the maturation profile of erythroid precursors from $\operatorname{Pr} \times 2^{-I-} \mathrm{Hbb}^{\text {th } 3 /+}$ 
A

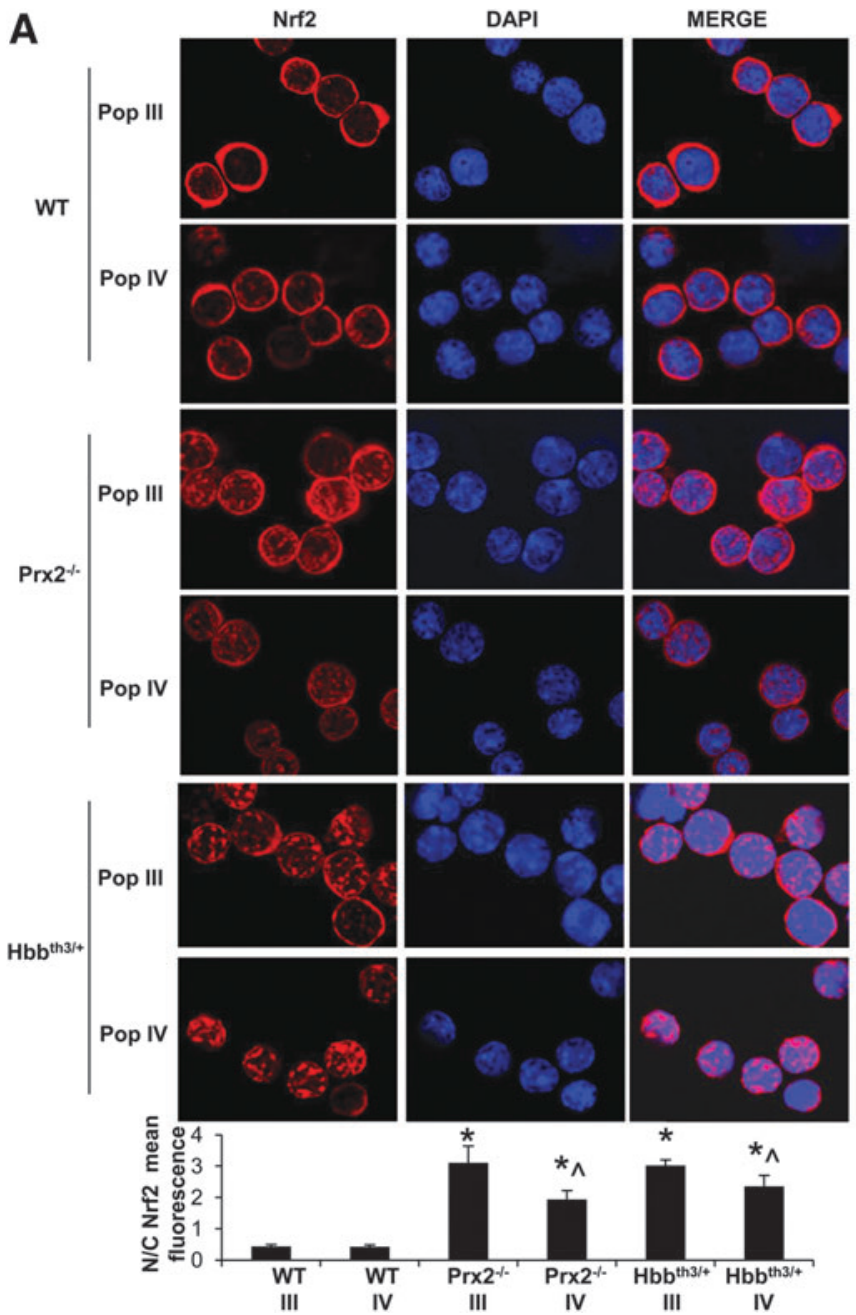

B
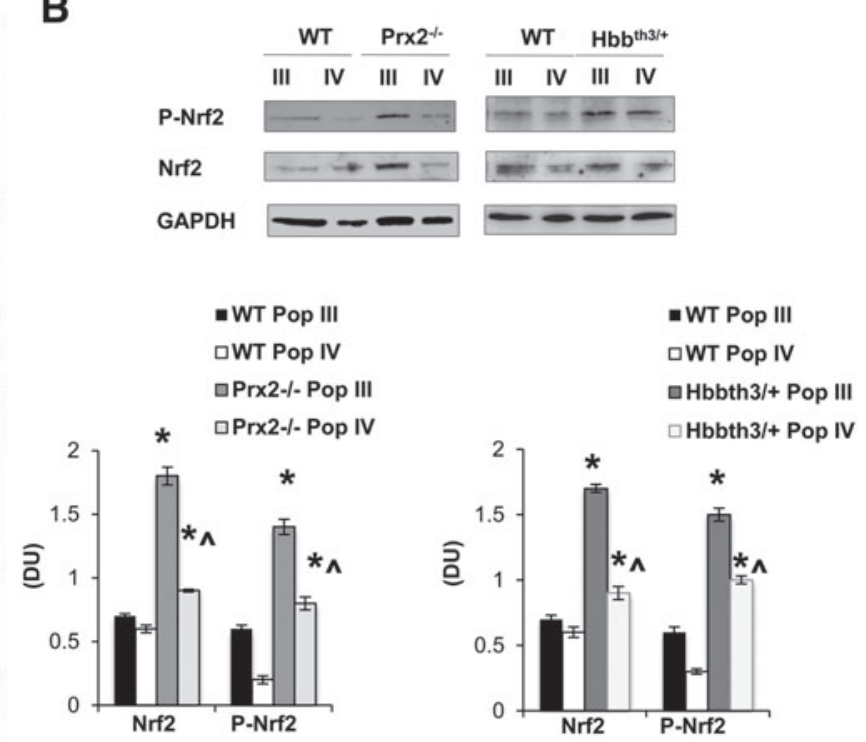

C

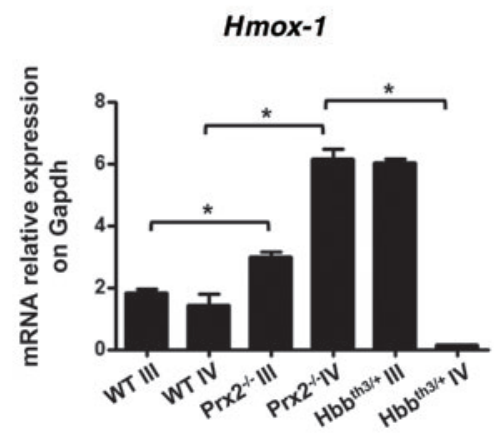

FIG. 2. Prx $2^{-/-}$and $\beta$-thalassemic $\left(\mathrm{Hbb}^{\text {th3/+}}\right)$ mouse erythroid precursors show activation of Nrf2 and upregulation of cyoprotective genes in response to oxidative stress. (A) Nrf2 immunostaining of sorted polychromatic erythroblasts (Pop III) and orthochromatic erythroblasts (Pop IV) from bone marrow of WT Prx $2^{-/-}$and $\mathrm{Hbb}^{\text {th } 3 /+}$ mice. Cells were FACS sorted, cytospun onto glass slides, immunostained with anti-Nrf2 antibody, and counterstained with DAPI. Lower panel. The mean fluorescence was measured in the nucleus and cytoplasm of 30 cells using Image $\mathbf{J}$ software. Data are presented as means \pm SD $(n=6) ; * p<0.05$ compared with WT; ${ }^{\wedge} p<0.05$ Pop III versus Pop IV. (B) Wb analysis of phospho-Nrf2 (P-Nrf2) and Nrf2 in sorted polychromatic erythroblasts (Pop III) and orthochromatic erythroblasts (Pop IV) from bone marrow of WT, Prx $2^{-1-}$, and $\mathrm{Hbb}^{\text {th } 3 /+}$ mice. GAPDH was used as a protein loading control. One representative gel from the other five with similar results is presented. Lower panel. Relative quantification of immunoreactivity of phospho-Nrf2 (P-Nrf2) and Nrf2 in sorted polychromatic erythroblasts (Pop III) and orthochromatic erythroblasts (Pop IV). Data are shown as means \pm SD $(n=6)$. ${ }^{*} p<0.05$ compared with WT; ${ }^{\wedge} p<0.05$ Pop III versus Pop IV. (C) RT-PCR expression of HO-1 (Hmox1) on sorted mouse polychromatic (Pop III) and orthochromatic (Pop IV) erythroblasts from bone marrow of WT, Prx $2^{-1-}$, and $\mathrm{Hbb}^{3 \mathrm{th} /}{ }^{+}$mice. Experiments were performed in triplicate. Error bars represent the SDs (mean \pm SD); $* p<0.05$. The graphs were created using the Software GraphPad Prism 6. DAPI, 4',6-diamidino-2-phenylindole; FACS, fluorescence-activated cell sorting; GAPDH, glyceraldehyde 3-phosphate dehydrogenase; HO-1, heme-oxygenase-1; Nrf2, nuclear factor-erythroid 2; RT-PCR, real time polymerase chain reaction; Wb, Western blot. To see this illustration in color, the reader is referred to the web version of this article at www.liebertpub.com/ars

bone marrow was similar to that of $\mathrm{Hbb}^{\text {th } 3 /+}$ mice, we found a significant reduction in basophilic and polychromatic erythroblasts with an increase in orthochromatic erythroblasts from spleens of $\operatorname{Prx}^{-/-} \mathrm{Hbb}^{\text {th } 3 /+}$ compared with $\mathrm{Hbb}^{\text {th } 3 /+}$ mice (Fig. 4A, B). These differences might be related to the two different compartments of erythropoiesis: the bone marrow and the spleen, the latter of which, we suggest, represents a highly pro-oxidant environment compared with the bone marrow. In fact, the ROS levels were similar in erythroid precursors from bone marrow of
$\mathrm{Prx}^{-1-} \mathrm{Hbb}^{\text {th } 3 /+}$ and $\mathrm{Hbb}^{\text {th } 3 /+}$ mice, but we found a significant increase of ROS production in all erythroid precursors from the spleen of $\operatorname{Prx} 2^{-1-} \mathrm{Hbb}^{\text {th } 3 /+}$ compared with $\mathrm{Hbb}^{\text {th3/+ }}$ (Fig. 4C). The amount of early apoptotic orthochromatic erythroblasts was markedly increased in both the bone marrow and spleen from Prx $2^{-/-} \mathrm{Hbb}^{\text {th } 3 /+}$ compared with $\mathrm{Hbb}^{\text {th } 3 /+}$ mice (Fig. 4D).

These findings indicate that the absence of Prx 2 markedly affects $\beta$-thalassemic erythropoiesis by amplifying oxidative stress and ineffective erythropoiesis. 
Table 1. Hematological Parameters and Red Cell INDICES IN WILD-TYPE, $\beta$-ThALASSEMIC $\left(\mathrm{HBB}^{3 \mathrm{TH} /+}\right)$, AND PRX $2^{-l-} \beta$ Thalassemic (PRX $\left.2^{-l-} \mathrm{HBB}^{3 \mathrm{Th} /+}\right)$ Mice

\begin{tabular}{lccc}
\hline & $\begin{array}{c}\text { Wild-type } \\
\text { mice } \\
(\mathrm{n}=15)\end{array}$ & $\begin{array}{c}\mathrm{Hbb}^{3 \mathrm{th} /+} \\
\text { mice } \\
(\mathrm{n}=12)\end{array}$ & $\begin{array}{c}\mathrm{Prx}^{-/-} \\
\mathrm{Hbb}^{3 \mathrm{th} /+} \\
\text { mice }(\mathrm{n}=12)\end{array}$ \\
\hline Hct (\%) & $46.1 \pm 1.4$ & $28.7 \pm 0.3^{*}$ & $26.1 \pm 0.2^{* \circ}$ \\
$\mathrm{Hb}(\mathrm{g} / \mathrm{dl})$ & $14.8 \pm 0.5$ & $9.3 \pm 0.2^{*}$ & $8.07 \pm 0.1^{* \circ}$ \\
$\mathrm{MCV}(\mathrm{fl})$ & $51.3 \pm 0.2$ & $34.6 \pm 0.6^{*}$ & $35.1 \pm 0.7^{*}$ \\
$\mathrm{MCH}(\mathrm{g} / \mathrm{dl})$ & $15.9 \pm 0.7$ & $9.1 \pm 0.03^{*}$ & $8.9 \pm 0.04^{*}$ \\
$\mathrm{CH}(\mathrm{pg})$ & $14.4 \pm 0.08$ & $9.7 \pm 0.2$ & $9.8 \pm 0.06^{*}$ \\
RDW(\%) & $12.5 \pm 0.2$ & $33.2 \pm 0.9^{*}$ & $30.5 \pm 1.2^{*}$ \\
Retics (\%) & $2.9 \pm 0.6$ & $27.7 \pm 3.8^{*}$ & $36.4 \pm 1.3^{* \circ}$ \\
\hline
\end{tabular}

${ }^{*} p<0.05$ compared with wild-type mice; ${ }^{\circ} p<0.05$ compared with b- thal ${ }^{3 \mathrm{th} /}$ - mice.

$\mathrm{Hb}$, hemoglobin; Hct, hematocrit; $\mathrm{MCH}$, mean corpuscular hemoglobin; MCV, mean corpuscular volume; RDW, red cell distribution width; Retics, reticulocytes.
In Prx2 ${ }^{-/-} H b b^{\text {th } 3 /+}$, the absence of Prx2 is associated with activation of Nrf2 in orthochromatic erythroblasts

Since our data indicate the central role of the interplay between Prx 2 and Nrf2 to limit oxidative stress in $\beta$-thalassemic erythropoiesis, we evaluated Nrf2 activation in polychromatic and orthochromatic erythroblasts from $\operatorname{Prx} 2^{-/-} \mathrm{Hbb}^{\text {th } 3 /+}$ mice. As shown in Figure 5A, Nrf2 was similarly activated in polychromatic erythroblasts from $\operatorname{Prx} 2^{-/-} \mathrm{Hbb}^{\text {th } 3 /+}$ and $\mathrm{Hbb}^{\text {th } 3 /+}$ mice, but it was significantly more activated in orthochromatic erythroblasts from $\operatorname{Pr} \times 2^{-/-} \mathrm{Hbb}^{\text {th } 3 /+}$ mice compared with those from $\mathrm{Hbb}^{\text {th } 3 /+}$ mice. This finding implies a critical role for Nrf2 at late stages of terminal erythroid differentiation as an adaptive mechanism in response to amplified oxidative stress due to the absence of Prx 2 on $\beta$-thalassemic erythropoiesis. The expression of a set of ARE responsive antioxidant genes such as HO-1 (Hmoxl), glutathione S-transferase (Gstm), and nqol was upregulated in polychromatic from $\operatorname{Prx}^{-/-} \mathrm{Hbb}^{\text {th } 3 /+}$ compared with $\mathrm{Hbb}^{\text {th } 3 /+}$ mice (Fig. 5B). However, Hmox-1 and Nqol were the only ARE responsive antioxidant genes upregulated in orthochromatic erythroblasts from $\operatorname{Pr} \times 2^{--1} \mathrm{Hbb}^{\text {th } 3 /+}$ compared with $\mathrm{Hbb}^{\text {th } 3 /+}$ mice.
A

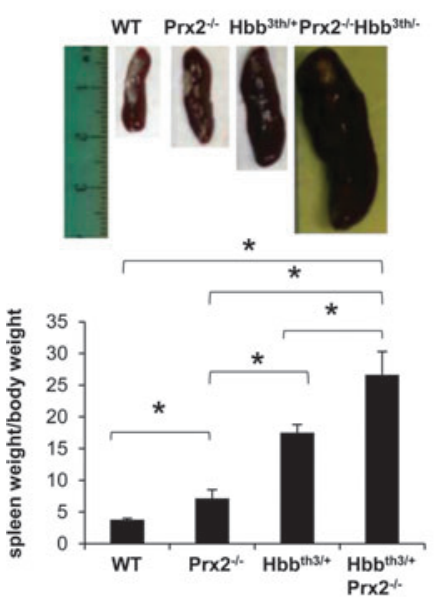

B

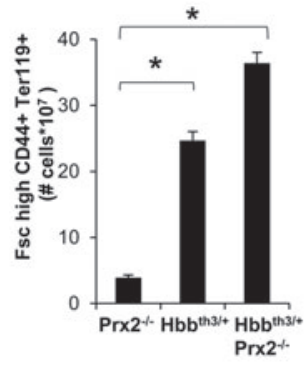

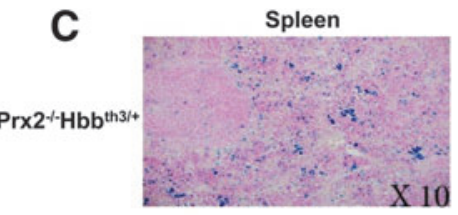
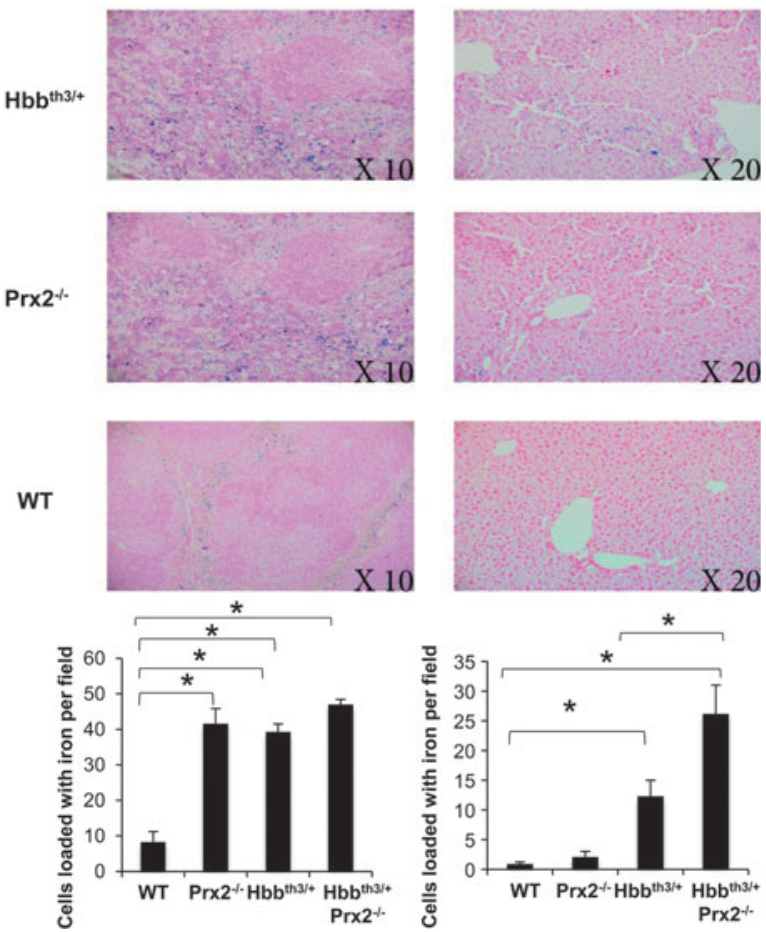

FIG. 3. The absence of Prx2 increases $\beta$-thalassemic ineffective erythropoiesis and iron-overload in Prx $2^{-\prime-}$ Hbb $^{\text {th3/+ }}$ mice. (A) Macroscopic appearance of spleen from WT, Prx2 $2^{-/-}$Hbb $^{\text {th } 3 /+}$, and Prx $2^{-/-} \mathrm{Hbb}^{\text {th } 3 /+}$ mice. One representative image from the other 12 with similar results is presented. Lower panel. Spleen weight/mouse weight ratio of WT, Prx $2^{-l-}$, $\mathrm{Hbb}^{\text {th } 3 /+}$, and Prx $2^{-l-} \mathrm{Hbb}^{\text {th } 3 /+}$ mice. Data are shown as means \pm SD $(n=6) ; * p<0.05$. (B) Number of cells Fsc high CD44+ TER119+ in the spleen from Prx $2^{-/-}, \mathrm{Hbb}^{\text {th } 3 /+}$, and Prx $2^{-/-} \mathrm{Hbb}^{\text {th } 3 /+}$ mice. Data are shown as means $\pm \operatorname{SD}(n=10) ;{ }^{*} p<0.05 .(\mathbf{C})$ Iron staining (Pearl's Prussian blue) in spleen and liver from WT, Prx $2^{-/-}, \mathrm{Hbb}^{\text {th } 3 /+}$, and Prx $2^{-1-} \mathrm{Hbb}^{\text {th } 3 /+}$ mice. One representative image from the other six with similar results is presented. Lower panel. Quantification of iron staining on Pearl's Prussian blue spleen and liver from WT, Prx $2^{-/-}, \mathrm{Hbb}^{\text {th } 3 /+}$, and Prx $2^{-1-} \mathrm{Hbb}^{\text {th } 3 /+}$ mice (see Materials and Methods). Data are shown as means \pm SD $(n=10) ; * p<0.05$. To see this illustration in color, the reader is referred to the web version of this article at www.liebertpub.com/ars 

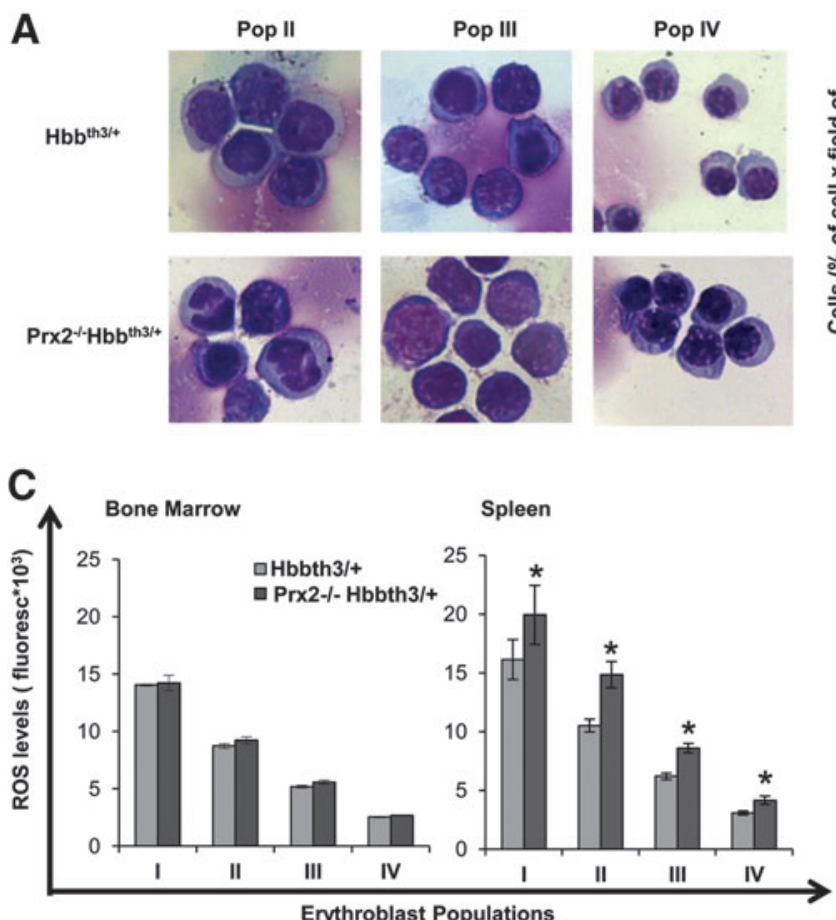
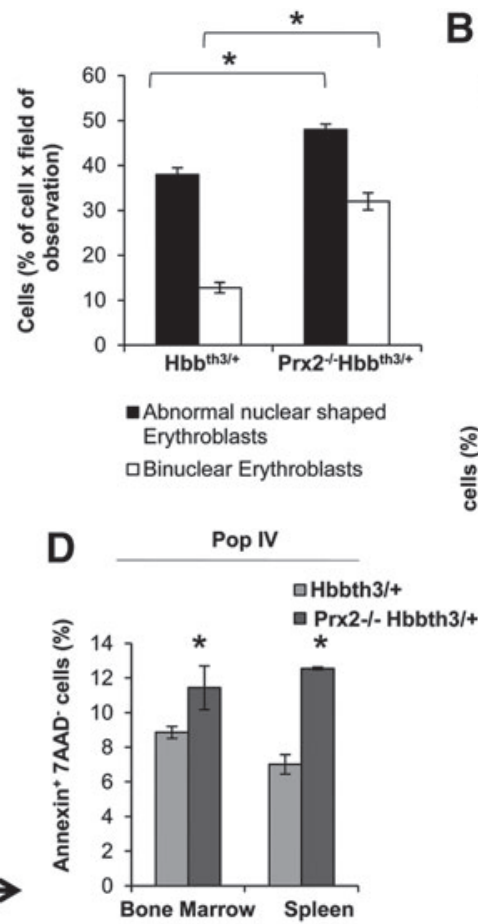

B

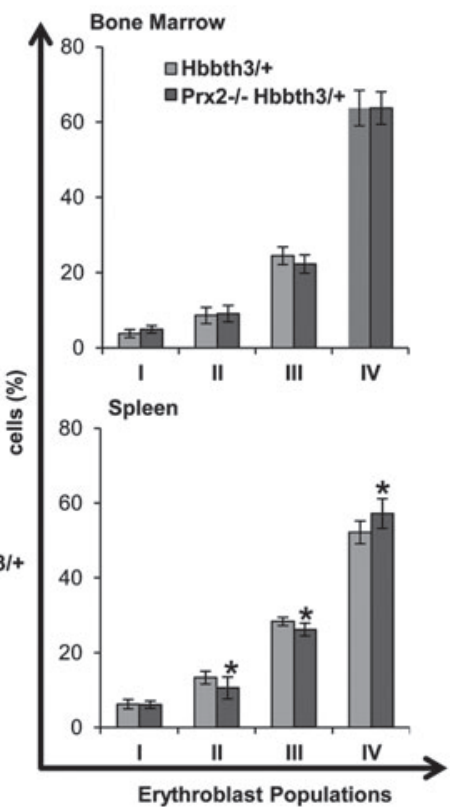

FIG. 4. The absence of $\operatorname{Prx} 2$ worsens $\beta$-thalassemic ineffective erythropoiesis, with increased ROS levels and cell apoptosis in Prx2 $2^{-/-} \mathbf{H b b}^{\mathrm{th} 3 /+}$ mice. (A) Left panel. Morphology of sorted erythroid from $\mathrm{Hbb}^{\mathrm{th} 3 /+}$ and Prx $2^{-/-} \mathrm{Hbb}^{\mathrm{th} 3 /+}$ mice. Cytospins were stained with May-Grunwald-Giemsa. Cells were imaged under oil at $100 \times$ magnification using a Panfluor objective with 1.30 numeric aperture on a Nikon Eclipse DS-5M camera and processed with Digital Slide (DS-L1) Nikon. One representative image from a total of 10 for each mouse strain. Right panel. Abnormal nuclear-shaped erythroblasts and binuclear erythroblasts from $\mathrm{Hbb}^{\text {th } 3 /+}$ and $\operatorname{Prx} 2^{-1-} \mathrm{Hbb}^{\text {th } 3 /+}$ mice evaluated on cytospin stained with May-Grunwald-Giemsa. Data are presented as means \pm SD $\left(n=10\right.$ from each strain); ${ }^{*} p<0.05$. (B) Cyto-fluorimetric analysis of maturation pattern of erythroid precursors from the bone marrow (upper panel) and spleen (lower panel) of $\mathrm{Hbb}^{\mathrm{th} 3 /+}$ and $\operatorname{Prx}^{-1-} \mathrm{Hbb}^{\text {th } 3 /+}$ mice using the following surface markers: CD44 and TER119. Population I corresponds to pro-erythroblasts; population II corresponds to basophilic erythroblasts; population III corresponds to polychromatic erythroblasts; and population IV corresponds to orthochromatic erythroblasts. Data are presented as means \pm SD $(n=10) ; * p<0.05$ compared with $\mathrm{Hbb}^{\text {th } 3 /+}$. (C) ROS levels from erythroid precursors from the bone marrow (left panel) and spleen (right panel) of $\mathrm{Hbb}^{\text {th } 3 /+}$ and Prx $2^{-/-} \mathrm{Hbb}^{\text {th } 3 /+}$ mice using the following surface markers: CD44 and TER119 (see Supplementary Materials and Methods). Data are presented as means \pm SD ( $n=10$ from each strain); ${ }^{*} p<0.05$ compared with $\mathrm{Hbb}^{\text {th } 3 /+}$ mice. (D) Amount of Annexin- $\mathrm{V}^{+}-7-\mathrm{AAD}^{-}$cells (early apoptosis) in sorted orthochromatic erythroblasts (population IV) from either bone marrow of $\mathrm{Hbb}^{\text {th } 3 /+}$ and Prx $2^{-1-} \mathrm{Hbb}^{\text {th } 3 /+}$ mice or spleen of $\mathrm{Hbb}^{\text {th } 3 /+}$ and $\operatorname{Prx} 2^{-/-} \mathrm{Hbb}^{\text {th } 3 /+}$ mice. Data are presented as means $\pm \mathrm{SD}\left(n=10\right.$ from each strain); ${ }^{*} p<0.05$ compared with $\mathrm{Hbb}^{\text {th } 3 /+}$ mice. To see this illustration in color, the reader is referred to the web version of this article at www.liebertpub.com/ars

\section{Recombinant PEP1 Prx2 fusion protein ameliorates $\beta$-thalassemic erythropoiesis}

Finally, we tested the ability of recombinant PEP-1 Prx2 (PEP1 Prx2) fusion protein to ameliorate ROS levels and decrease ineffective erythropoiesis of $\mathrm{Hbb}^{\text {th } 3 /+}$ mice. PEPPrx 2 has been previously shown to be able to penetrate cells and to efficiently counteract oxidative stress in two models of neurodegenerative diseases $(5,20)$. Thus, we carried out a preliminary study to determine the PEP1 Prx2 dosage required to impact stress erythropoiesis. We found that PEP1 Prx2, when administrated at $1 \mathrm{mg} / \mathrm{kg} / \mathrm{d}$ ip for 4 weeks, significantly increased $\mathrm{Hct}, \mathrm{Hb}$ levels and $\mathrm{MCV}$ and $\mathrm{MCH}$ and significantly reduced reticulocyte count in $\mathrm{Hbb}^{\text {th } 3 /+}$ mice (Fig. 6A). $\mathrm{Hbb}^{\text {th } 3 /+}$ PEP1 Prx2-treated mice showed a reduction in red cell membrane-associated $\alpha$-globin precipitates, suggesting an amelioration of $\mathrm{Hbb}^{\text {th } 3 /+}$ erythropoiesis (Fig. 6B). This was also associated with a significant reduction in circulating erythroblasts compared with $\mathrm{Hbb}^{\text {th3/+ }}$ vehicle-treated mice
$\left(\mathrm{Hbb}^{\mathrm{th} 3 /+} v s . \mathrm{Hbb}^{\mathrm{th} 3 /+}\right.$ PEP1 Prx2 mice $38.1 \pm 6.4$ vs. $8.0 \pm$ $3.3 \%$ ). We observed a reduction in iron staining in the spleens from PEP1 Prx2 treated $\mathrm{Hb}^{\text {th } 3 /+}$ mice compared with vehicletreated mice (Fig. 6C). The profile of $\mathrm{Hbb}^{\mathrm{th} 3 /+}$ erythroid precursors in the bone marrow showed a significant increase in basophilic erythroblasts (pop II) and a reduction in $\mathrm{Hbb}^{\mathrm{th} 3 /+}$ orthochromatic erythroblasts (Fig. 6D). The ROS levels were significantly decreased in all erythroid populations from both bone marrow and spleens of PEP1 Prx2-treated $\mathrm{Hbb}^{\text {th } 3 /+}$ mice compared with vehicle-treated mice (Fig. 6E). This finding was also paralleled by a significant reduction in apoptosis of $\mathrm{Hbb}^{\text {th3/+ }}$ orthochromatic erythroblasts from bone marrow of PEP1 Prx2-treated $\mathrm{Hbb}^{\text {th } 3 /+}$ mice (Fig. 6F). It is of interest to note that PEP1 Prx2 treatment reduced Nrf2 activation in $\mathrm{Hbb}^{\text {th } 3 /+}$ orthochromatic erythroblasts compared with vehicletreated $\mathrm{Hbb}^{\text {th } 3 /+}$ mice (Supplementary Fig. S4A). Similar results were also observed in PEP1 Prx2-treated Prx $2^{-/-}$mice (Supplementary Fig. S4B, C). No changes in hematological parameters, reticulocyte count (data not shown), and 
A

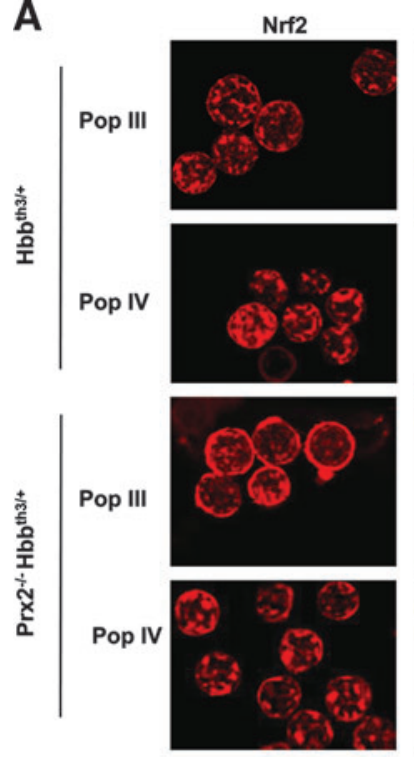

DAPI
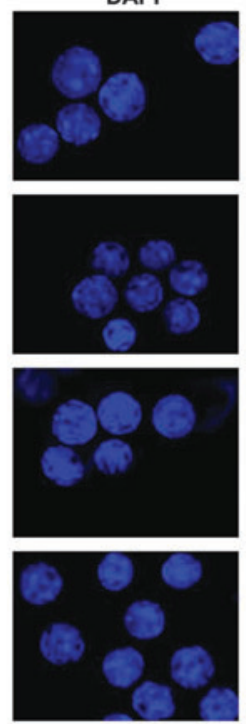

MERGE
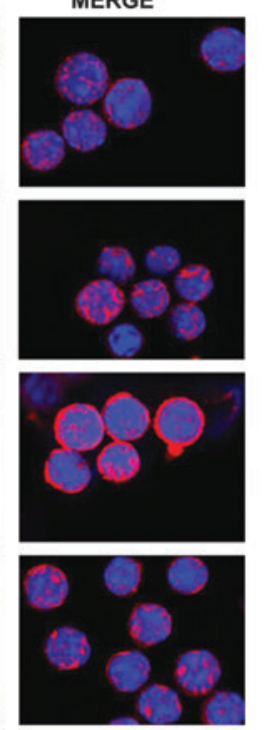

Gstm

C
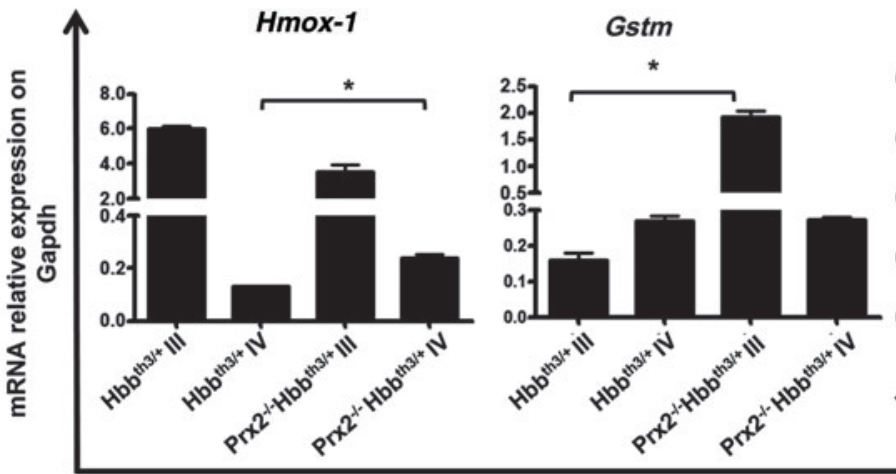

B
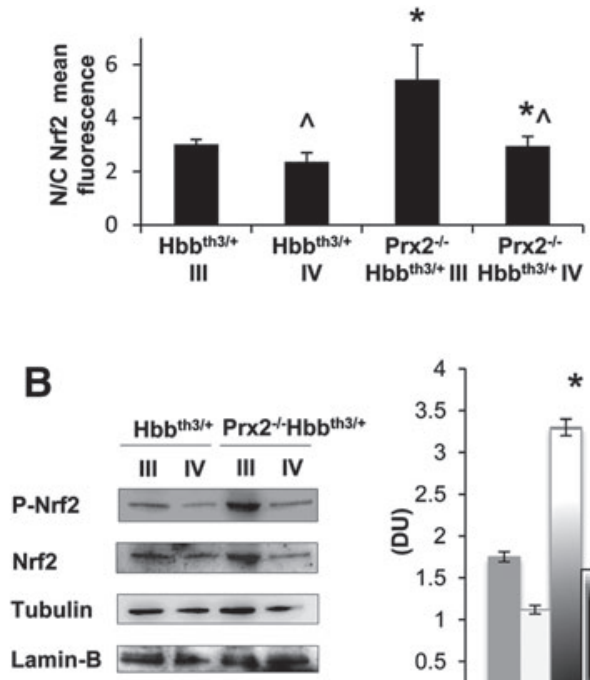

B

P-Nrf2

$\mathrm{Nrf2}$

Lamin-B

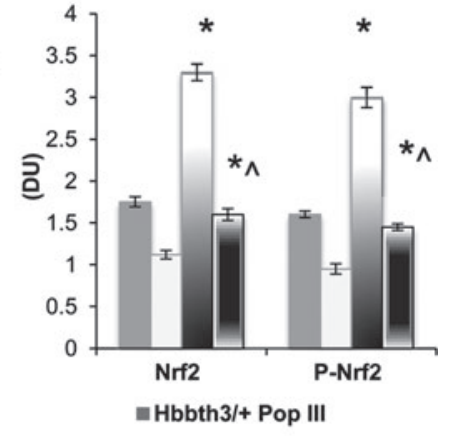

Nqo1

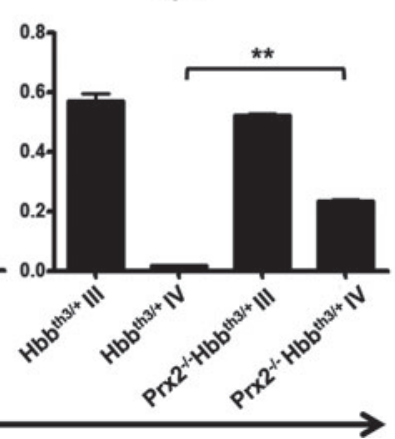

- Hbbth3/+ Pop IV

a. Prx2-/-Hbbth3/+ Pop III

aPrx2-/-Hbbth3/+ Pop IV

FIG. 5. In Prx ${ }^{-/-} \mathrm{Hbb}^{\text {th } 3 /+}$ mice, the absence of Prx2 is associated with activation of Nrf2 in orthochromatic erythroblasts and upregulation of ARE-responsive genes. (A) Nrf2 immunostaining of sorted polychromatic erythroblasts (Pop III) and orthochromatic erythroblasts (Pop IV) from bone marrow of $\mathrm{Hbb}^{\text {th } 3 / 9}$ and Prx2 ${ }^{-/-} \mathrm{Hbb}^{\text {th } 3 /+}$ mice. Cells were FACS sorted, cytospun onto glass slides, immunostained with anti-Nrf2 antibody, and counterstained with DAPI. Right panel. The mean fluorescence was measured in the nucleus and cytoplasm of 30 cells using Image J software. Data are presented as means \pm SD; ${ }^{*} p<0.05$ compared with $\mathrm{Hbb}^{\text {th } 3 /+}(n=10) ;{ }^{\wedge} p<0.05$ Pop III versus Pop IV. (B) Wb analysis of phospho-Nrf2 (P-Nrf2) and Nrf2 in sorted polychromatic erythroblasts (Pop III) and orthochromatic erythroblasts (Pop IV) from bone marrow of $\mathrm{Hbb}^{\mathrm{th} 3 /+}$ and $\operatorname{Prx}^{-/-} \mathrm{Hbb}^{\mathrm{th} 3 /+}$ mice. Tubulin and laminin-B were used as protein loading controls. One representative gel from the other five with similar results is presented. Right panel. Relative quantification of immunoreactivity of phospho-Nrf2 (p-Nrf2) and Nrf2 in sorted polychromatic erythroblasts (Pop III) and orthochromatic erythroblasts (Pop IV) from bone marrow of $\mathrm{Hbb}^{\mathrm{th} 3 /+}$ and Prx $2^{-l-} \mathrm{Hbb}^{\mathrm{th} 3 /+}$ mice. Data are shown as means $\pm \mathrm{SD}(n=6){ }^{*} p<0.05$ compared with $\mathrm{Hbb}^{\text {th } 3 /+} ; \hat{p}<0.05$ Pop III versus Pop IV. (C) RT-PCR expression of HO-1 (Hmox1), Gstm, and Nqol on sorted mouse polychromatic and orthochromatic erythroblasts from bone marrow of $\mathrm{Hbb}^{\text {th } 3 /+}$ and $\mathrm{Prx}^{-1-} \mathrm{Hbb}^{\text {th } 3 /+}$ mice. Experiments were performed in triplicate. Error bars represent the SDs (mean $\pm \mathrm{SD}$ ); ${ }^{*} p<0.05 ; * * \leq \leq 0.001$. The graphs were created using the Software GraphPad Prism 6. Gstm, glutathione S-transferase; nqo1, NAD(P)H dehydrogenase quinone 1. To see this illustration in color, the reader is referred to the web version of this article at www.liebertpub.com/ars

erythropoiesis were evident in PEP Prx2-treated WT mice compared with vehicle-treated WT (Supplementary Fig. S4D).

\section{Discussion}

In this study, we documented a novel interplay between $\operatorname{Prx} 2$ and Nrf2 to limit oxidative stress in $\beta$-thalassemic erythropoiesis. The abnormalities in erythropoiesis of $\operatorname{Pr} x 2^{-1-}$ mice suggest that $\operatorname{Prx} 2$ is required to interface between the physiological oxidative stress and maturation events involved in erythropoiesis (Fig. 1). This is also supported by the amelioration of $\operatorname{Prx} 2^{-/-}$mouse erythropoiesis in response to NAC antioxidant treatment (Supplementary Fig. S1B). $\beta$-Thalassemia is a paradigmatic example of stress erythropoiesis characterized by severe oxidative stress with upregulation of Prx2 expression (13, 33, 43). The similarities between $\operatorname{Prx} 2^{-1-}$ and $\beta$-thalassemic erythropoiesis further support the key role of Prx 2 in stress erythropoiesis.

At the crossroad of the redox response is the transcriptional factor Nrf2 (18), which might co-operate with endogenous antioxidant system(s) such as $\operatorname{Prx} 2$ against severe oxidative stress during erythropoiesis. Indeed, Prx2 $2^{-1-}$ and $\mathrm{Hbb}^{\text {th } 3 /+}$ 
A
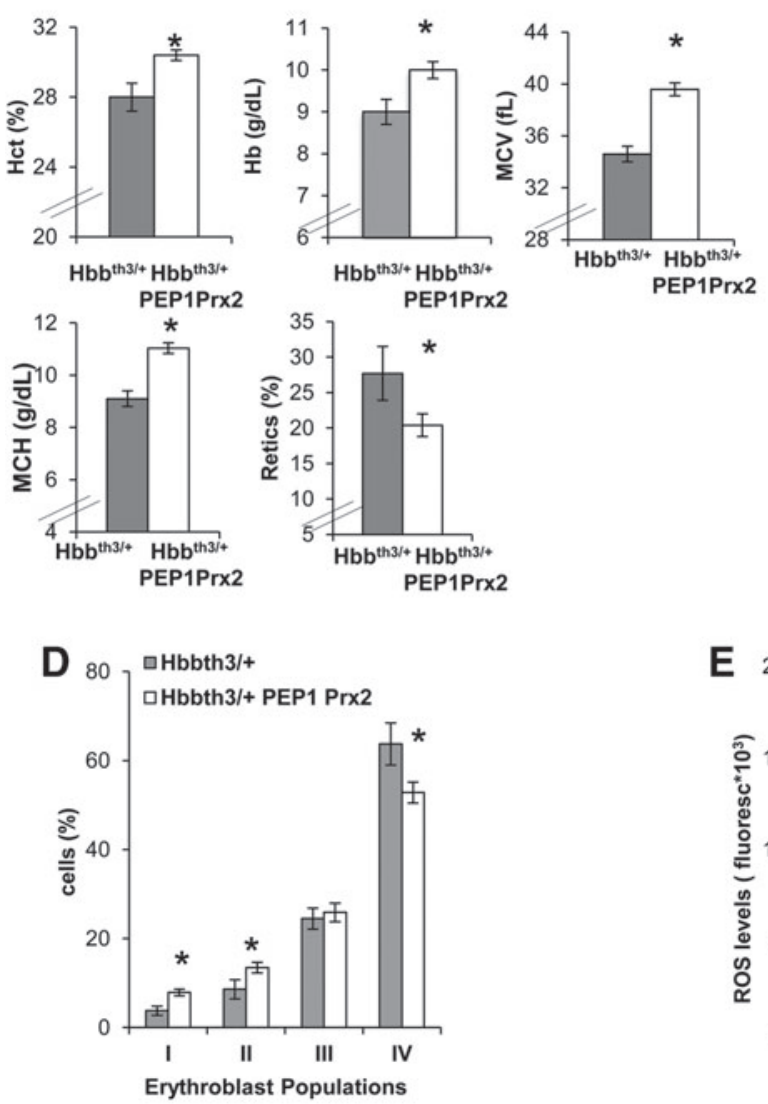

B

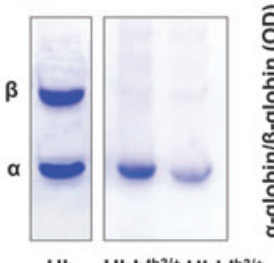

$\mathrm{Hb} \mathrm{Hbb}^{\text {th } 3 /+} \mathrm{Hbb}^{\text {th } 3 /+}$ PEP1Prx2
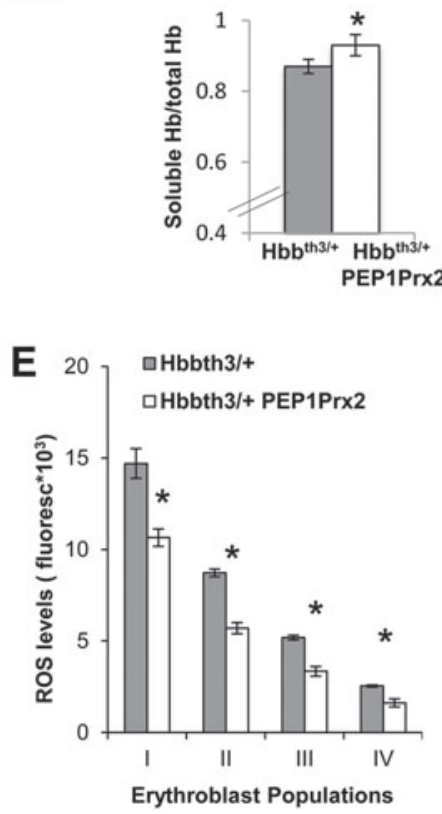

C
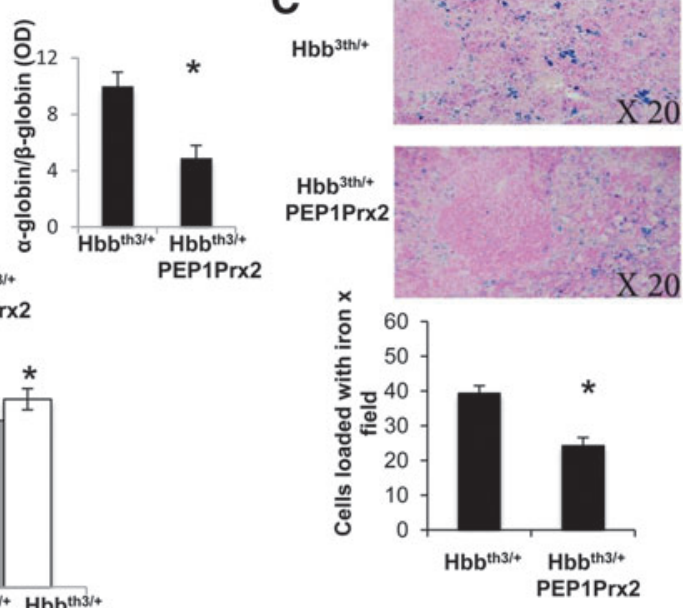

$\mathbf{F}$

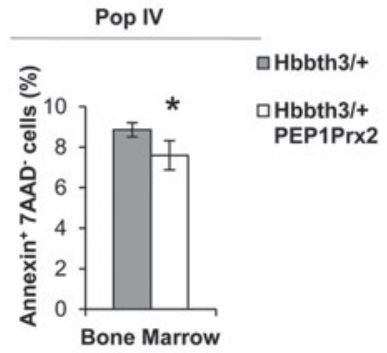

FIG. 6. In $\mathrm{Hbb}^{\text {th } 3 /+}$ mice, treatment with recombinant PEP1-Prx2 fusion protein ameliorates $\beta$-thalassemic anemia, beneficially affecting circulating red cells and erythropoiesis. (A) Hematological parameters: $\mathrm{Hct}, \mathrm{Hb}, \mathrm{MCV}, \mathrm{MCH}$, and retics in $\mathrm{Hbb}^{\text {th } 3 /+}$ mice with and without PP1Prx2 treatment (see Materials and Methods). Data are presented as means \pm SD $(n=6) .{ }^{*} p<0.05$ compared with vehicle-treated $\mathrm{Hbb}^{\text {th } 3 /+}$. (B) Upper panel. TAU gel electrophoresis of red cell membrane from WT and $\mathrm{Hbb}^{\text {th } 3 /+}$ mice with and without PEP1 Prx2 treatment. On the right, quantification of gel bands (OD) expressed as $\alpha$ globin to $\beta$-globin ratio to $\mathrm{Hb}$. Data are shown as means $\pm \mathrm{SD}(n=3) ;{ }^{*} p<0.05$ compared with vehicle-treated $\mathrm{Hbb}^{\text {th } 3 /+}$ mice. Lower panel. Total and soluble $\mathrm{Hb}$ measured in hemolysates from $\mathrm{Hbb}^{\mathrm{th} 37+}$ mice with and without PEP1 Prx 2 treatment. Data are shown as means $\pm \mathrm{SD}(n=3) ; * p<0.05$ compared with vehicle-treated $\mathrm{Hbb}^{\text {th } 3 /+}$ mice. (C) Iron staining (Pearl's Prussian blue) in spleen and liver from $\mathrm{Hbb}^{\text {this/ }}$ mice with and without PP1Prx2 treatment. One representative image from the other six with similar results is presented. Lower panel. Quantification of iron staining on Pearl's Prussian blue spleen and liver from Hbb ${ }^{\text {th3/ }}$ mice with and without PP1Prx2 treatment mice. Data are shown as means $\pm \operatorname{SD}(n=6) . * p<0.05$ compared with vehicle-treated $\mathrm{Hbb}^{\text {th } 3 /+}$. (D) Cyto-fluorimetric analysis of maturation pattern of erythroid precursors from the bone marrow of $\mathrm{Hbb}^{\text {th } 3 /+}$ mice with and without PP1Prx2 treatment using the following surface markers: CD44 and TER119. Population I corresponds to proerythroblasts; population II corresponds to basophilic erythroblasts; population III corresponds to polychromatic erythroblasts; and population IV corresponds to orthochromatic erythroblasts. Data are presented as means $\pm \operatorname{SD}(n=6) ;{ }^{*} p<0.05$ compared with vehicle-treated $\mathrm{Hbb}^{\mathrm{th} / 1+}$ mice. (E) ROS levels in erythroid precursors from bone marrow of $\mathrm{Hb}^{\mathrm{th} 3 /+}$ mice with and without PP1Prx2 treatment. Data are presented as means \pm SD $(n=6) ; * p<0.05$ compared with vehicle-treated $\mathrm{Hbb}^{\mathrm{th} 3 /+}$ mice. (F) Annexin $\mathrm{V}^{+}-7-\mathrm{AAD}^{-}$sorted orthochromatic erythroblasts (population IV) from bone marrow of $\mathrm{Hbb}^{\text {th } 3 /+}$ mice with and without PP1Prx2 treatment. Data are presented as means $\pm \mathrm{SD}(n=6) ;{ }^{*} p<0.05$ compared with vehicle-treated $\mathrm{Hbb}^{\text {th } 3 /+}$ mice. $\mathrm{Hb}$, hemoglobin; Hct, hematocrit; $\mathrm{MCH}$, mean corpuscular hemoglobin; MCV, mean corpuscular volume. To see this illustration in color, the reader is referred to the web version of this article at www.liebertpub.com/ars

erythroblasts showed increased activation of Nrf2 compared with WT cells. The transient activation of Nrf2 in WT erythroblasts in response to exogenous oxidative stress such as PHZ indicates that Nrf2 is generally inactive under physiological condition and can be transiently activated in response to acute severe oxidative damage. On the other hand, in $\beta$ thalassemia or in $\operatorname{Prx} 2^{-/-}$mice characterized by chronic oxidative stress, Nrf2 is constitutively activated. This working model for Nrf2 is also supported by previous reports on
$\mathrm{Nrf}^{-1-}$ mice, which show only mild hematological phenotype only in aged mice with reduced antioxidant protection (38). In $\mathrm{Px}^{-/-}$and $\mathrm{Hbb}^{\text {th } 3 /+}$ mouse erythroblasts, the activation of $\mathrm{Nrf} 2$ was associated with upregulation of ARE-response genes such as HO-1 (Fig. 2C). The differences in HO-1 gene expression between $\mathrm{Px} 2^{-/-}$and $\mathrm{Hbb}^{\text {th } 3 /+}$ orthochromatic erythroblasts might be related to the relative heme deficiency previously reported by us and others in $\beta$-thalassemic erythroid precursors in the late stages of erythropoiesis $(6,12)$. 
The absence of Prx 2 worsened the $\beta$-thalassemic hematologic phenotype in $\operatorname{Prx} 2^{-/-} \mathrm{Hbb}^{\text {th } 3 /+}$ mice, indeed supporting the key role of Prx 2 in stress erythropoiesis. This was also associated with further activation of $\mathrm{Nrf} 2$ in $\operatorname{Prx} 2^{-1-}$ $\mathrm{Hbb}^{\text {th } 3 /+}$ mice compared with $\mathrm{Hbb}^{\text {th } 3 /+}$ mice and the upregulation of various ARE-related genes such as Gstm, Hmox-1, and nqol (Fig. 5C). We were not surprised to find differences in timing of upregulation of Nrf2-related ARE-genes, since it has been shown that the induction and modulation of the battery of ARE-genes is more efficient in cellular protection against toxic events than the induction of only a few of them (10). These findings suggest that $\operatorname{Pr} \times 2^{-/-} \mathrm{Hbb}^{\text {th } 3 /+}$ mice require a resetting of the balance between oxidative stress and antioxidant systems in favor of antioxidant systems to sustain $\beta$-thalassemic erythropoiesis. As a proof of concept of the role of Prx 2 in pathological erythropoiesis, we administrated fused recombinant PEP1-Prx2 (PEP1Prx2) to $\mathrm{Hbb}^{\text {th } 3 /+}$ mice. In PEP1Prx2-treated $\mathrm{Hbb}^{\text {th } 3 /+}$ mice, we observed decreased ineffective erythropoiesis in $\beta$-thalassemic mice, indicating that a potentiation of endogenous antioxidant systems may limit the oxidation damage and ensure cell survival during $\beta$-thalassemic erythropoiesis.

Thus, we propose the interplay between Prx2, a key antioxidant system, and Nrf2 as an oxidative response transcriptional factor, in cellular adaptation to oxidative stress, resulting in upregulation of antioxidant (ARE)-genes required to ensure cell survival. It is of interest to note that a similar interplay between Nrf2 and seleno-proteins has been previously reported to impact ROS production in erythrocytes from seleno-protein-deficient mice (24).

Our working model of how Prx 2 and Nrf2 may co-operate in stress erythropoiesis is shown in Figure 7. In WT mice, Prx 2 controls the intrinsic oxidative stress present during cellular maturation events; but in the presence of acute exogenous oxidative stress (PHZ), Prx 2 interplays with Nrf2 to contain the toxic effects of high ROS levels. The absence of Prx 2 promotes ineffective erythropoiesis and activation of Nrf2, which is similarly induced in $\beta$-thalassemic erythroid precursors. When Prx 2 is knocked out in $\mathrm{Hbb}^{\text {th } 3 /+}$ mice, in the face of increased ineffective erythropoiesis, the ROS levels and the activation of Nrf2 are further increased compared with $\mathrm{Hbb}^{\text {th } 3 /+}$ mice. Treatment with PEP1-Prx2 markedly reduced ROS levels and cell apoptosis in $\mathrm{Hbb}^{\text {th } 3 /+}$ mice with an amelioration of $\beta$-thalassemic ineffective erythropoiesis and reduction in Nrf2 activation. Our data shed new light on adaptive mechanisms against oxidative stress mediated through Prx2 and Nrf2 during erythropoiesis to minimize oxidative damage and also suggest new possible therapeutic options in modulation of endogenous antioxidant systems to downregulate pathological erythropoiesis.

\section{Materials and Methods}

\section{Drugs and chemicals}

$\mathrm{NaCl}, \mathrm{Na}_{3} \mathrm{VO}_{4}$, phosphate-buffered saline (PBS) phosphate buffer, bicine, benzamidine, $\beta$-mercaptoethanol, bromophenol blue, sodium dodecyl sulphate, $\mathrm{NaF}$, ethylenediaminetetraaceticacid, May-Grunwald stain, Giemsa stain, PHZ hydrochloride, albumin from bovine serum (bovine serum albumin [BSA]), and glycerol were obtained from Sigma/Aldrich (St. Louis, MO); protease inhibitor cocktail tablets were from Roche (Basel, Switzerland); dithiotreithol was from Fluka (Buchs, Switzerland); Triton X-100 was from GE Healthcare Life Sciences (Little Chalfont, United Kingdom); 40\% Acrylamide/Bis Solution, 37.5:1 was from BIO-RAD (Hercules, CA); Dulbecco's Phosphate-Buffered Saline was from Lonza (Verviers,

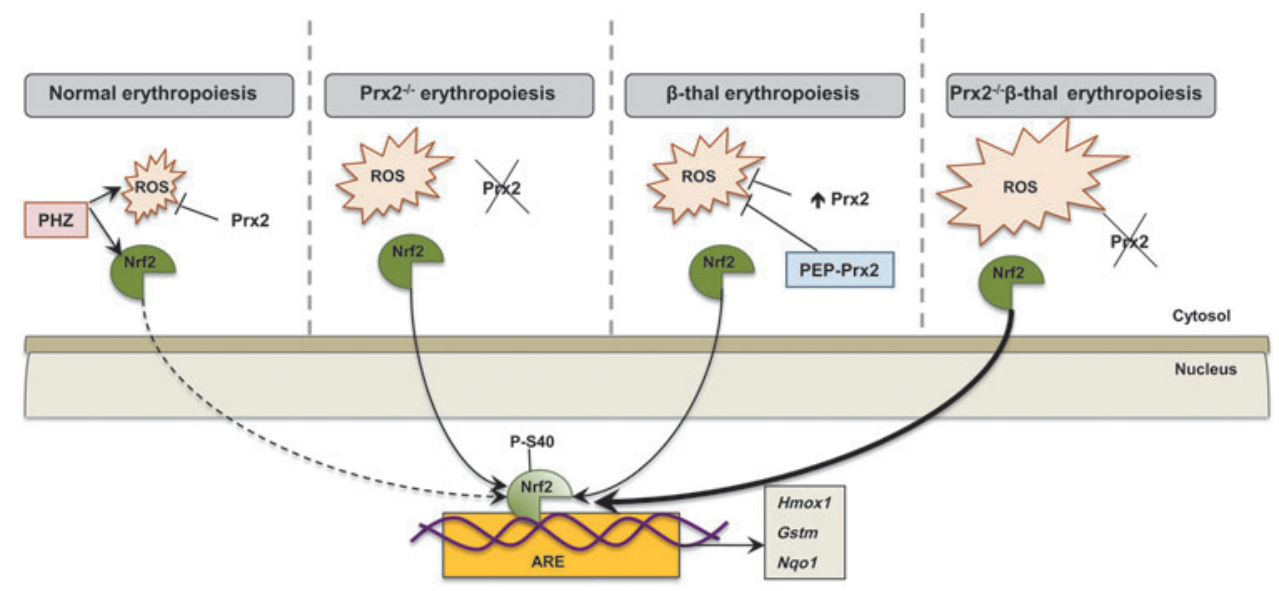

FIG. 7. Schematic diagram of the working model proposed for Prx2 cooperating with Nrf2 to limit oxidative damage in $\beta$-thalassemic erythropoiesis. In WT mice, the physiological generation of ROS during erythropoiesis is controlled by antioxidant systems such as Prx2 and Nrf2 transcriptional factor is inactive. The acute oxidative stress induced by PHZ activates Nrf2, which, in turn, upregulates ARE-genes of antioxidant systems such as HO-1 (Hmoxl), Gstm, or nqo1. The absence of Prx 2 promotes ineffective erythropoiesis and increases ROS levels with associated activation of Nrf2 as a backup mechanism to control oxidative stress. In $\beta$-thalassemic erythroid precursors, despite the upregulation of Prx2, oxidative stress promotes the activation of Nrf2, which upregulates ARE-genes for antioxidant systems. PEP-Prx2 treatment ameliorates ineffective erythropoiesis and reduced ROS levels. In Prx $2^{-/-} \mathrm{Hbb}^{\text {th } 3 /+}$ mice, the absence of Prx 2 worsens $\beta$ thalassemic hematological phenotype and ineffective erythropoiesis with a further increase in ROS levels and further activation of Nrf2. Thus, in stress erythropoiesis, Prx 2 and Nrf2 act to contain the toxic effects of high ROS levels to ensure cell survival. ARE, antioxidant responsive element; PHZ, phenylhydrazine. To see this illustration in color, the reader is referred to the web version of this article at www.liebertpub.com/ars 
Belgium); and Luminata Forte and Luminata Classico Hrp solutions were from Merck Millipore (Armstadt, Germany).

\section{Mouse strains and design of the study}

C57B6/2J mice as WT controls, $\operatorname{Prx} 2^{-/-}$mice and $\mathrm{Hbb}^{\text {th3/+ }}$, as a mouse model of $\beta$-thalassemia intermedia were used in this study $(13,15,16,35) . \mathrm{Hbb}^{\text {th } 3 /+}$ and $\operatorname{Prx} 2^{-/-}$had the same C57BL6J background as the WT mice and were backcrossed for 17 generations to generate $\operatorname{Prx} 2^{-/-} \mathrm{Hbb}^{\text {th } 3 /+}$ mice. The genotype of $\operatorname{Pr} \times 2^{-/-} \mathrm{Hbb}^{\text {th } 3 /+}$ mice was validated at each generation. The Institutional Animal Experimental Committee, University of Verona (CIRSAL) and the Italian Ministry of Health approved the experimental protocols. Based on our preliminary data and previous reports, we used 3-4 month-old female mice from the four mouse strains (16).

Where indicated, Prx $2^{-1-}$ mice were treated with NAC at the dosage of $100 \mathrm{mg} / \mathrm{kg} / \mathrm{day}$ (in $\mathrm{NaCl} 0.9 \%, \mathrm{NaOH} 36 \mathrm{~m} M$, pH 9.4; ip) or vehicle only for 3 weeks $(9 \mathrm{a}, 31) . \mathrm{Hbb}^{\text {th } 3 /+}$ and Prx $2^{-l-}$ mice were treated with PEP1Prx2 (in PBS) at the dosage of $1.25 \mathrm{mg} / \mathrm{kg} /$ day ip or vehicle for 4 weeks $(5,20)$.

Hematological parameters, red cell indices, and reticulocyte count were determined as previously reported $(4,8,9$, 13). Blood was collected with retro-orbital venipuncture in anesthetized mice using heparined microcapillary tubes. Hematological parameters were evaluated on a Bayer Technicon Analyser ADVIA. Hct and $\mathrm{Hb}$ were manually determined $(8,13)$.

Determination of $\alpha$-globin and $\beta$-globin ration was carried out as previously reported by Dussiot et al. (11).

\section{Flow cytometric analysis of mouse erythroid precursors and cell sorting of murine bone marrow erythroblasts}

Flow cytometric analysis of erythroid precursors from the bone marrow and spleen of mice from the four strains was carried out as previously described using the CD44-TER-119 strategy (28). Population II, III, and IV corresponding to basophilic erythroblasts, polychromatic erythroblasts, and orthochromatic erythroblasts were sorted from bone marrow of mice from the four strains as previously reported (28). Sorted cells were used for (i) morphological analysis of erythroid precursors on cytospin preparations stained with May Grunwald-Giemsa; (ii) immunofluorescence assay for Nrf2; (iii) immune-blot analysis for Nrf2 and P-Nrf2; and (iv) real time-polymerase chain reaction analysis $(13,28)$. Details on primers used are reported in Supplementary Table S1. In immunofluorescence assay, Nrf2 quantification was performed using the ImageJ software (http://imagej.nih.gov/ij/) as previously described (40).

For immunoblot-analysis, the following specific antibodies were used: anti Nrf2-phospho-S40, anti Nrf2 (Abcam, Cambridge, United Kingdom), anti glyceraldehyde 3phosphate dehydrogenase (Sigma/Aldrich), anti beta-Tubulin (clone E7; DSHB, Iowa, IA), and anti Lamin B (Santa Cruz Biotechnology, Santa Cruz, CA), used as loading controls. Images were acquired using Image Quant Las Mini 4000 Digital Imaging System (GE Healthcare Life Sciences), and densitometric analysis was performed using the ImageQuant TL software (GE Healthcare Life Sciences) (4, 13, 23). Analysis of apoptotic orthochromatic erythroblasts was carried out on the CD44-Ter-119 gated cells using the
Annexin-V PE Apoptosis detection kit (eBioscience, San Diego, CA) following the manufacturer's instructions (15). Flow cytometric analysis was carried out with the FACSCanto $^{\text {TM }}$ flow cytometer (Becton Dickinson, San Jose, CA).

\section{Analysis of ROS levels on different populations of erythroid precursors}

The ROS levels from erythroid precursors were determined using the General Oxidative Stress Indicator CM-H2DCFDA (LifeTechnologies, Carlsbad, CA) on erythroid precursors as previously described, (31) with minor changes. Briefly, CD44PE (Miltenyi Biotec, Bergisch Gladbach, Germany), TER-119 APC, CD45 APC-eFluor 780, GR1 APC-Cy7, and CD11b APC-Cy7 stained cells (28) from mouse bone marrow or spleen were incubated with CM-H2DCFDA (10 $\mu M$ in PBS, BSA $1 \%$ at $37^{\circ} \mathrm{C}$ for $20 \mathrm{~min}$ ). Cells were then washed once with PBS BSA $1 \%$, stained in ice with 7-AAD, and analyzed by an FACS Canto II flow cytometer (Becton Dickinson).

\section{Generation of recombinant-PEP-1 Prx2 fusion protein}

The fusion protein PEP1Prx 2 was generated as previously reported $(5,20)$. PEP1Prx 2 was intraperitonealy administered once a day at the dosage of $1.25 \mathrm{mg} / \mathrm{kg}$ for 4 weeks based on previous reports $(5,20)$.

\section{Histological analysis of spleen and liver}

Spleen and liver were, immediately after mice dissection, formalin fixed and paraffin embedded. For each paraffin block, after $3 \mu \mathrm{m}$-thick sections were cut, they were stained with hematoxylin eosin, Masson's trichrome, and MayGrunwald-Giemsa. Tissue iron was stained using Perls prussian blue stain after treatment with diluted hydrochloric acid to prevent ferric ions from binding proteins. The analysis of iron staining was performed on four different fields at magnification $\times 200$ by two pathologists (A.J., C.L.) blinded to the experimental groups. Results were expressed as the mean number of cells loaded with iron on Perls' stain.

\section{Statistical analysis}

Data were analyzed using either $t$-test or the two-way analysis of variance for repeated measures between the mice of various genotypes. A difference with a $p$ value $<0.05$ was considered significant.

\section{Acknowledgments}

This work was supported by PRIN (L.D.F. and A.I.: 201228PNX83) and FUR_UNIVR (L.D.F.).

\section{Authorship and Contributions}

A.M., L.D.F., N.M., and A.I. designed the experiments, analyzed data, and wrote this article; X.A. analyzed the data and wrote this article; A.J., C.L. carried out the histological analysis; A.M., A.S., and L.D.F. carried out the experiments; L.D.F. performed the molecular experiments and analyzed the data; and S.Y.C. and D.W.K. generated the PEPPrx2.

\section{Author Disclosure Statement}

No competing financial interests exist. 


\section{References}

1. Amer J, Goldfarb A, and Fibach E. Flow cytometric measurement of reactive oxygen species production by normal and thalassaemic red blood cells. Eur J Haematol 70: 8490, 2003.

2. An X, Schulz VP, Li J, Wu K, Liu J, Xue F, Hu J, Mohandas N, and Gallagher PG. Global transcriptome analyses of human and murine terminal erythroid differentiation. Blood 123: 3466-3477, 2014.

3. Bozzini CE, Barrio Rendo ME, Devoto FC, and Epper CE. Studies on medullary and extramedullary erythropoiesis in the adult mouse. Am J Physiol 219: 724-728, 1970.

4. Brugnara $\mathrm{C}$ and de Franceschi L. Effect of cell age and phenylhydrazine on the cation transport properties of rabbit erythrocytes. J Cell Physiol 154: 271-280, 1993.

5. Choi JH, Kim DW, Yoo DY, Jeong HJ, Kim W, Jung HY, Nam SM, Kim JH, Yoon YS, Choi SY, and Hwang IK. Repeated administration of PEP-1-Cu,Zn-superoxide dismutase and PEP-1-peroxiredoxin-2 to senescent mice induced by D-galactose improves the hippocampal functions. Neurochem Res 38: 2046-2055, 2013.

6. De Franceschi L, Bertoldi M, De Falco L, Santos Franco S, Ronzoni L, Turrini F, Colancecco A, Camaschella C, Cappellini MD, and Iolascon A. Oxidative stress modulates heme synthesis and induces peroxiredoxin-2 as a novel cytoprotective response in beta-thalassemic erythropoiesis. Haematologica 96: 1595-1604, 2011.

7. De Franceschi L, Bertoldi M, Matte A, Santos Franco S, Pantaleo A, Ferru E, and Turrini F. Oxidative stress and beta-thalassemic erythroid cells behind the molecular defect. Oxid Med Cell Longev 2013: 985210, 2013.

8. De Franceschi L, Brugnara C, and Beuzard Y. Dietary magnesium supplementation ameliorates anemia in a mouse model of beta-thalassemia. Blood 90: 1283-1290, 1997.

9. De Franceschi L, Turrini F, del Giudice EM, Perrotta S, Olivieri O, Corrocher R, Mannu F, and Iolascon A. Decreased band 3 anion transport activity and band 3 clusterization in congenital dyserythropoietic anemia type II. Exp Hematol 26: 869-873, 1998.

9a. De Franceschi L, Turrini F, Honczarenko M, Ayi K, Rivera A, Fleming MD, Law T, Mannu F, Kuypers FA, Bast A, van der Vijgh WJF, and Brugnara $\mathrm{C}$. In vivo reduction of erythrocyte oxidant stress in a murine model of betathalassemia. Haematologica, 89: 1287-1298, 2004.

10. Duffy S, So A, and Murphy TH. Activation of endogenous antioxidant defenses in neuronal cells prevents free radical-mediated damage. J Neurochem 71: 69-77, 1998.

11. Dussiot M, Maciel TT, Fricot A, Chartier C, Negre O, Veiga J, Grapton D, Paubelle E, Payen E, Beuzard Y, Leboulch P, Ribeil JA, Arlet JB, Cote F, Courtois G, Ginzburg YZ, Daniel TO, Chopra R, Sung V, Hermine O, and Moura IC. An activin receptor IIA ligand trap corrects ineffective erythropoiesis in beta-thalassemia. Nat Med 20: 398-407, 2014.

12. Forget B. The thalassemia syndromes. In: Hematology: Basic Principles and Practice, edited by Hoffman RBE and Shatill SJ, et al. Philadelphia, PA: Churchill Livingstone, 1999, pp. 485-492.

13. Franco SS, De Falco L, Ghaffari S, Brugnara C, Sinclair DA, Matte A, Iolascon A, Mohandas N, Bertoldi M, An X, Siciliano A, Rimmele P, Cappellini MD, Michan S, Zoratti E, Anne J, and De Franceschi L. Resveratrol accelerates erythroid maturation by activation of FoxO3 and amelio- rates anemia in beta-thalassemic mice. Haematologica 99: 267-275, 2014.

14. Friedman JS, Lopez MF, Fleming MD, Rivera A, Martin FM, Welsh ML, Boyd A, Doctrow SR, and Burakoff SJ. SOD2-deficiency anemia: protein oxidation and altered protein expression reveal targets of damage, stress response, and antioxidant responsiveness. Blood 104: 25652573, 2004.

15. Gardenghi S, Ramos P, Marongiu MF, Melchiori L, Breda L, Guy E, Muirhead K, Rao N, Roy CN, Andrews NC, Nemeth E, Follenzi A, An X, Mohandas N, Ginzburg Y, Rachmilewitz EA, Giardina PJ, Grady RW, and Rivella S. Hepcidin as a therapeutic tool to limit iron overload and improve anemia in beta-thalassemic mice. J Clin Invest 120: 4466-4477, 2010.

16. Guo S, Casu C, Gardenghi S, Booten S, Aghajan M, Peralta R, Watt A, Freier S, Monia BP, and Rivella S. Reducing TMPRSS6 ameliorates hemochromatosis and beta-thalassemia in mice. J Clin Invest 123: 1531-1541, 2013.

17. Han YH, Kim SU, Kwon TH, Lee DS, Ha HL, Park DS, Woo EJ, Lee SH, Kim JM, Chae HB, Lee SY, Kim BY, Yoon do Y, Rhee SG, Fibach E, and Yu DY. Peroxiredoxin II is essential for preventing hemolytic anemia from oxidative stress through maintaining hemoglobin stability. Biochem Biophys Res Commun 426: 427-432, 2012.

18. Hayes JD and Dinkova-Kostova AT. The Nrf2 regulatory network provides an interface between redox and intermediary metabolism. Trends Biochem Sci 39: 199-218, 2014.

19. Itoh K, Wakabayashi N, Katoh Y, Ishii T, O'Connor T, and Yamamoto M. Keap1 regulates both cytoplasmic-nuclear shuttling and degradation of Nrf2 in response to electrophiles. Genes Cells 8: 379-391, 2003.

20. Jeong HJ, Yoo DY, Kim DW, Yeo HJ, Cho SB, Hyeon J, Park JH, Park J, Eum WS, Hwang HS, Won MH, Hwang IK, and Choi SY. Neuroprotective effect of PEP-1-peroxiredoxin2 on CA1 regions in the hippocampus against ischemic insult. Biochim Biophys Acta 1840: 2321-2330, 2014.

21. Johnson RM, Ho YS, Yu DY, Kuypers FA, Ravindranath $\mathrm{Y}$, and Goyette GW. The effects of disruption of genes for peroxiredoxin-2, glutathione peroxidase-1, and catalase on erythrocyte oxidative metabolism. Free Radic Biol Med 48: 519-525, 2010.

22. Jonsson TJ and Lowther WT. The peroxiredoxin repair proteins. Subcell Biochem 44: 115-141, 2007.

23. Kalish BT, Matte A, Andolfo I, Iolascon A, Weinberg O, Ghigo A, Cimino J, Siliciano A, Hirsch E, Federti E, Puder M, Brugnara C, and De Franceschi L. Dietary omega-3 fatty acids protect against vasculopathy in a transgenic mouse model of sickle cell disease. Haematologica pii. haematol 2015.124586, 2015.

24. Kawatani Y, Suzuki T, Shimizu R, Kelly VP, and Yamamoto M. Nrf2 and selenoproteins are essential for maintaining oxidative homeostasis in erythrocytes and protecting against hemolytic anemia. Blood 117: 986-996, 2011.

25. Kwon TH, Han YH, Hong SG, Lee DJ, Ha HL, Kang SW, Li W, Yoon do Y, and Yu DY. Reactive oxygen species mediated DNA damage is essential for abnormal erythropoiesis in peroxiredoxin II(-/-) mice. Biochem Biophys Res Commun 424: 189-195, 2012.

26. Lee JM, Chan K, Kan YW, and Johnson JA. Targeted disruption of Nrf2 causes regenerative immune-mediated 
hemolytic anemia. Proc Natl Acad Sci U S A 101: 97519756, 2004.

27. Lee TH, Kim SU, Yu SL, Kim SH, Park DS, Moon HB, Dho SH, Kwon KS, Kwon HJ, Han YH, Jeong S, Kang SW, Shin HS, Lee KK, Rhee SG, and Yu DY. Peroxiredoxin II is essential for sustaining life span of erythrocytes in mice. Blood 101: 5033-5038, 2003.

28. Liu J, Zhang J, Ginzburg Y, Li H, Xue F, De Franceschi L, Chasis JA, Mohandas N, and An X. Quantitative analysis of murine terminal erythroid differentiation in vivo: novel method to study normal and disordered erythropoiesis. Blood 121: e43-e49, 2013.

29. Low FM, Hampton MB, and Winterbourn CC. Peroxiredoxin 2 and peroxide metabolism in the erythrocyte. Antioxid Redox Signal 10: 1621-1630, 2008.

30. Ma Q. Role of nrf2 in oxidative stress and toxicity. Annu Rev Pharmacol Toxicol 53: 401-426, 2013.

31. Marinkovic D, Zhang X, Yalcin S, Luciano JP, Brugnara C, Huber T, and Ghaffari S. Foxo3 is required for the regulation of oxidative stress in erythropoiesis. J Clin Invest 117: 2133-2144, 2007.

32. Martin FM, Bydlon G, and Friedman JS. SOD2-deficiency sideroblastic anemia and red blood cell oxidative stress. Antioxid Redox Signal 8: 1217-1225, 2006.

33. Matte A, Low PS, Turrini F, Bertoldi M, Campanella ME, Spano D, Pantaleo A, Siciliano A, and De Franceschi L. Peroxiredoxin-2 expression is increased in beta-thalassemic mouse red cells but is displaced from the membrane as a marker of oxidative stress. Free Radic Biol Med 49: 457466, 2010.

34. This reference has been deleted.

35. Matte A, Pantaleo A, Ferru E, Turrini F, Bertoldi M, Lupo F, Siciliano A, Ho Zoon C, and De Franceschi L. The novel role of peroxiredoxin-2 in red cell membrane protein homeostasis and senescence. Free Radic Biol Med 76: 80-88, 2014.

36. Mitsuishi Y, Motohashi H, and Yamamoto M. The Keap1Nrf2 system in cancers: stress response and anabolic metabolism. Front Oncol 2: 200, 2012.

37. Miyamoto N, Izumi H, Miyamoto R, Kubota T, Tawara A, Sasaguri Y, and Kohno K. Nipradilol and timolol induce Foxo3a and peroxiredoxin 2 expression and protect trabecular meshwork cells from oxidative stress. Invest Ophthalmol Vis Sci 50: 2777-2784, 2009.

38. Niture SK, Kaspar JW, Shen J, and Jaiswal AK. Nrf2 signaling and cell survival. Toxicol Appl Pharmacol 244: $37-$ 42,2010

39. Niture SK, Khatri R, and Jaiswal AK. Regulation of Nrf2an update. Free Radic Biol Med 66: 36-44, 2014.

40. Noursadeghi M, Tsang J, Haustein T, Miller RF, Chain BM, and Katz DR. Quantitative imaging assay for NFkappaB nuclear translocation in primary human macrophages. J Immunol Methods 329: 194-200, 2008.

41. Park J, Lee S, Lee S, and Kang SW. 2-cys peroxiredoxins: emerging hubs determining redox dependency of Mammalian signaling networks. Int J Cell Biol 2014: 715867, 2014.

42. Peslak SA, Wenger J, Bemis JC, Kingsley PD, Koniski AD, McGrath KE, and Palis J. EPO-mediated expansion of latestage erythroid progenitors in the bone marrow initiates recovery from sublethal radiation stress. Blood 120: 25012511, 2012.
43. Ribeil JA, Arlet JB, Dussiot M, Moura IC, Courtois G, and Hermine O. Ineffective erythropoiesis in beta-thalassemia. ScientificWorldJournal 2013: 394295, 2013.

44. Rund D and Rachmilewitz E. Beta-thalassemia. $N$ Engl J Med 353: 1135-1146, 2005.

45. Satoh T, Rezaie T, Seki M, Sunico CR, Tabuchi T, Kitagawa T, Yanagitai M, Senzaki M, Kosegawa C, Taira H, McKercher SR, Hoffman JK, Roth GP, and Lipton SA. Dual neuroprotective pathways of a pro-electrophilic compound via HSF-1-activated heat-shock proteins and Nrf2-activated phase 2 antioxidant response enzymes. $J$ Neurochem 119: 569-578, 2011.

46. Singh S, Vrishni S, Singh BK, Rahman I, and Kakkar P. Nrf2-ARE stress response mechanism: a control point in oxidative stress-mediated dysfunctions and chronic inflammatory diseases. Free Radic Res 44: 1267-1288, 2010 .

47. Sobotta MC, Liou W, Stocker S, Talwar D, Oehler M, Ruppert T, Scharf AN, and Dick TP. Peroxiredoxin-2 and STAT3 form a redox relay for $\mathrm{H}_{2} \mathrm{O}_{2}$ signaling. Nat Chem Biol 11: 64-70, 2015.

48. Thamsen M, Kumsta C, Li F, and Jakob U. Is overoxidation of peroxiredoxin physiologically significant? Antioxid Redox Signal 14: 725-730, 2011.

49. Won H, Lim S, Jang M, Kim Y, Rashid MA, Jyothi KR, Dashdorj A, Kang I, Ha J, and Kim SS. Peroxiredoxin-2 upregulated by NF-kappaB attenuates oxidative stress during the differentiation of muscle-derived $\mathrm{C} 2 \mathrm{C} 12$ cells. Antioxid Redox Signal 16: 245-261, 2012.

50. Wood ZA, Schroder E, Robin Harris J, and Poole LB. Structure, mechanism and regulation of peroxiredoxins. Trends Biochem Sci 28: 32-40, 2003.

Address correspondence to: Prof. Lucia De Franceschi Department of Medicine University of Verona-AOUI Verona Policlinico GB Rossi, P.le L Scuro, 10 Verona 37134 Italy

E-mail: lucia.defranceschi@univr.it

Date of first submission to ARS Central, December 29, 2014; date of acceptance, May 13, 2015.

$\begin{aligned} & \quad \text { Abbreviations Used } \\ & \text { 7-AAD }=7 \text {-aminoactinomycin D } \\ & \mathrm{ARE}=\text { antioxidant responsive element } \\ & \mathrm{BSA}=\text { bovine serum albumin } \\ & \mathrm{DAPI}=4^{\prime}, 6 \text {-diamidino-2-phenylindole } \\ & \mathrm{FACS}=\text { fluorescence-activated cell sorting; } \\ & \mathrm{GAPDH}=\text { glyceraldehyde } 3 \text {-phosphate dehydrogenase } \\ & \mathrm{Gstm}=\text { glutathione S-transferase } \\ & \mathrm{Hb}=\text { hemoglobin } \\ & \mathrm{Hct}=\text { hematocrit } \\ & \mathrm{HO}-1=\text { heme-oxygenase-1 } \\ & \mathrm{MCH}=\text { mean corpuscular hemoglobin } \\ & \mathrm{MCV}=\text { mean corpuscular volume }\end{aligned}$




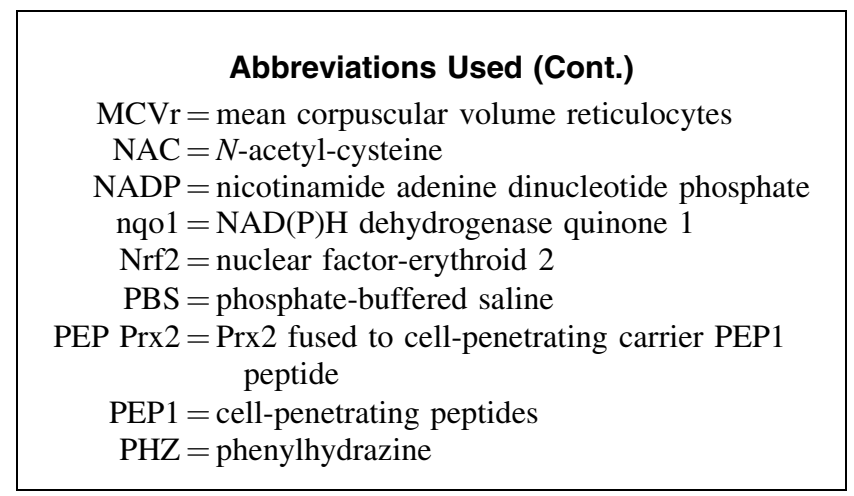

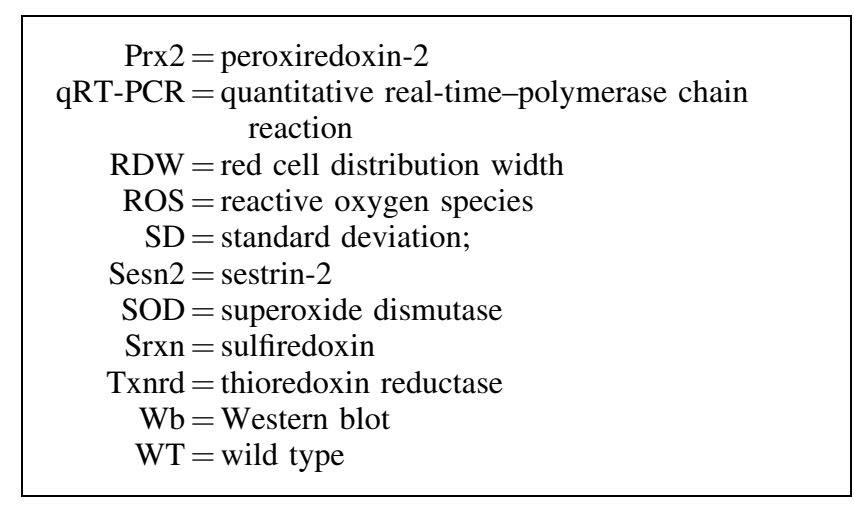

